Research Article

\title{
Stress-Strain Relation of Steel-Polypropylene-Blended Fiber-Reinforced Concrete under Uniaxial Cyclic Compression
}

\author{
Lihua Xu, Biao Li $\mathbb{D}^{D}$, Yin Chi ${ }^{D}$, Changning Li, Biao Huang, and Yuchuan Shi \\ School of Civil Engineering, Wuhan University, Wuhan, China \\ Correspondence should be addressed to Yin Chi; yin.chi@whu.edu.cn
}

Received 4 March 2018; Accepted 17 July 2018; Published 24 September 2018

Academic Editor: Antonio Caggiano

Copyright (c) 2018 Lihua Xu et al. This is an open access article distributed under the Creative Commons Attribution License, which permits unrestricted use, distribution, and reproduction in any medium, provided the original work is properly cited.

\begin{abstract}
This paper investigates the cyclic stress-strain behavior of steel-polypropylene-blended fiber-reinforced concrete (BFRC) under uniaxial cyclic compression. A total of 48 prism specimens were tested for different fiber volume fractions and aspect ratios. The results show that the introduction of blended fibers has synergetic effects on improving the cyclic behavior of concrete in terms of peak strength, postpeak ductility, hysteretic energy dissipation, and stiffness degradation. Moreover, the increase in the volume fractions of both steel and polypropylene fibers can lead to a remarkable decrease in plastic strain accumulation. Furthermore, the stiffness degradation ratio as well as the stress deterioration ratio of BFRC can be significantly alleviated in comparison with those of plain concrete, notwithstanding that the degradation amount is insensitive to the variations of fiber parameters. Subsequently, based on the test results, a constitutive model is developed to generalize the cyclic stress-strain responses of BFRC, with the contributions of blended fibers taken into account. The developed model is then verified by independent experimental results and other test data reported in the literature. It is observed that the prediction yields a close estimation of the cyclic compressive behavior of BFRC with varying fiber parameters.
\end{abstract}

\section{Introduction}

Concrete has been well acknowledged as one of the most widely used construction and building materials in civil engineering field. It is witnessed nowadays that a number of practical applications for large-scale concrete structures have emerged, such as high-rise buildings, large-span bridges, and nuclear power plants. However, plain concrete demonstrates explicitly its disadvantages that hinder its further application, e.g. susceptibility to cracking, low deformation threshold, and limited ductility, which at times have been the key determinants resulting in the selection of other alternative materials [1]. In an attempt to tackle the limitations, while reducing the dependency on steel reinforcement, extensive research studies have been undertaken, and to date, the majority of innovations published have succeeded in utilizing fiber-reinforced concrete (FRC) to effectively enhance the concrete properties [2-5]. In recent years, the concrete technology has resulted in a combination of different kinds of fibers, i.e., blended fiber-reinforced concrete
(BFRC) materials [6-10], in order to achieve a synergetic mechanical behavior.

It has to be mentioned that the cyclic stress-strain relation of BFRC plays an important role in the elastoplastic analysis of concrete members and directly determines the ductile and hysteretic behaviors of concrete structures subjected to seismic, explosive, and fatigue loads [11, 12]. Considerable efforts have been made to investigate the mechanical behaviors of plain and confined concrete under uniaxial cyclic loading [13-25]. The corresponding empirical constitutive models and formulae for generalizing the cyclic stress-strain responses of plain and confined concrete have been well established [26-28]. Moreover, some others have succeeded in the incorporation of fracture energy and damage-plastic concepts for cyclic constitutive modeling [29-32]. Those research outcomes have led to a great success in the prediction of concrete cyclic loading responses and serve as a base for the nonlinear analysis of concrete structural performance. In comparison with plain concrete, research studies on the cyclic mechanical behavior of FRC 
are rarely reported in the literature, with BFRC in particular [33-38]. Of the limited tests for FRC under cyclic loading, the study conducted by Otter and Naaman is worth quoting. They claimed that steel fiber-reinforced concrete (SFRC) behaves similarly as plain concrete except that the envelope varies with addition of fibers. The conclusion has been verified by other researchers. Thereafter, based on the test results, mathematical expressions analogous to plain concrete for predicting the cyclic stress-strain curve of SFRC under uniaxial compression were developed. With respect to BFRC, experimental investigations are found to be primarily concentrated on the performance of BFRC structural members $[39,40]$. Despite that, some constitutive formulations for modeling the stress-strain behaviors of BFRC under uniaxial and true triaxial loads have been established by a small amount of experimental investigations; however, the proposed models for BFRC are noted to be only suitable for monotonic loading cases $[7,8,10]$. The stress-strain relationship of BFRC under cyclic compressive load has not been investigated yet according to the author's knowledge. The effects of blended fiber and the multiple fiberreinforcing mechanism as well as the underlying blended effects on the concrete performance degradation and energy dissipation are rarely reported. The mechanical behavior and cyclic constitutive model of BFRC, which are of critical importance for civil engineering design and BFRC material applications, remain to be further elucidated.

The objective of this paper is to study the stress-strain relation of steel-polypropylene-blended fiber-reinforced concrete (BFRC) subjected to uniaxial cyclic compression. The influences of volume fraction and aspect ratio of blended fiber on the stress-strain responses and parameters of cyclic mechanical behavior were studied. Based on the experimental results, an empirical constitutive model was developed to generalize the cyclic compressive stress-strain responses of BFRC, with the effects of blended fiber taken into consideration.

\section{Experimental Program}

2.1. Materials and Specimens Preparation. Prismatic specimens with a dimension of $150 \mathrm{~mm} \times 150 \mathrm{~mm} \times 300 \mathrm{~mm}$ were employed in this study. The mix proportions of plain concrete designed according to the code JGJ 55-2011 [41] are given in Table 1, which is the same in [37]. Ordinary Portland cement type P.O. 42.5 was used as the binder. Crushed granitic rocks of sizes between $5 \mathrm{~mm}$ and $20 \mathrm{~mm}$ and normal river sands with a fineness modulus of 2.7 were used as the coarse aggregates and fine aggregates, respectively. The aggregate gradations of them are presented in Figure 1. A water reducer with a reducing rate of about $20 \%$ was adopted.

Two different types of fibers were considered in this study, namely, steel fiber (SF) and polypropylene fiber (PF), as shown in Figure 2. The corresponding properties are given in Table 2. According to the previous studies [7, 37], the volume fraction of SF ranging from $0.5 \%$ to $2.0 \%$ and the aspect ratio between 30 and 80 are recommended. In this work, the volume fractions of SF were selected as $1.0 \%, 1.5 \%$,
TABLE 1: Designed concrete mix proportions $\left(\mathrm{kg} / \mathrm{m}^{3}\right)$ [37].

\begin{tabular}{lccccc}
\hline Cement & Sand & Gravel & Water & Superplasticizer & $\begin{array}{c}\text { Water-cement } \\
\text { ratio }\end{array}$ \\
\hline 417 & 724 & 1086 & 175 & 2.1 & 0.42 \\
\hline
\end{tabular}

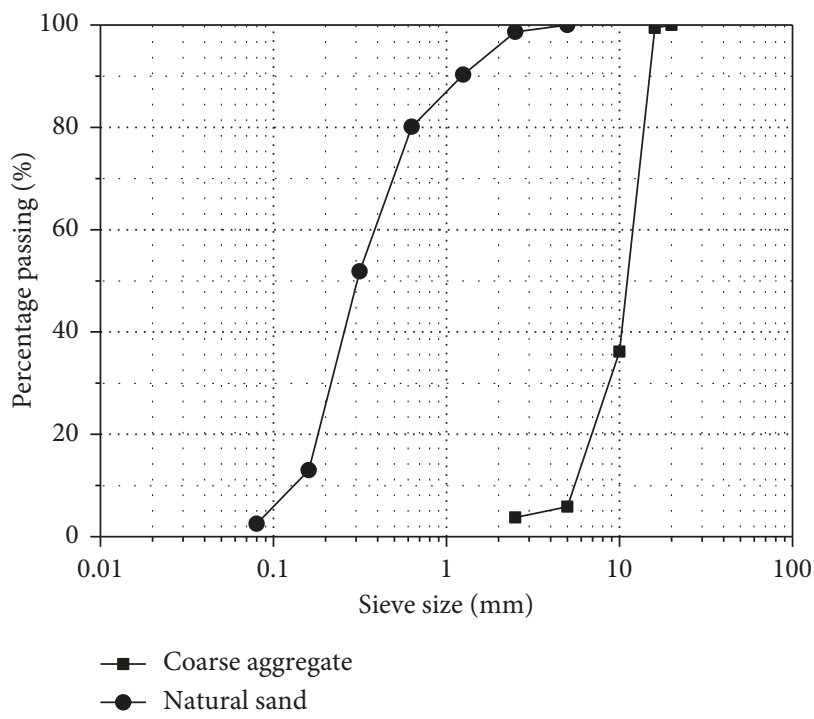

FIGURE 1: Grading curves for fine and coarse aggregates.

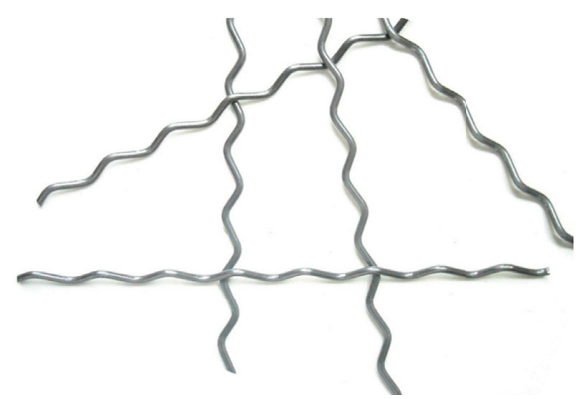

(a)

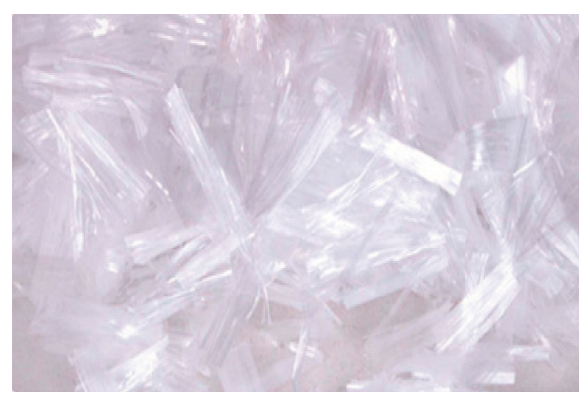

(b)

Figure 2: Respective features of (a) SF and (b) PF.

and $2.0 \%$, and the aspect ratios of 30,60 , and 80 were adopted. In addition, monofilament PFs with low volume fractions of $0.1 \%, 0.15 \%$, and $0.2 \%$ were, respectively, used in order to avoid the balling effect due to excessive dosage and ensure the even distribution of fibers. The lengths of PF having a fixed diameter of $48 \mu \mathrm{m}$ were selected to be $8 \mathrm{~mm}$, 
TABLE 2: Major properties of fibers.

\begin{tabular}{|c|c|c|c|c|c|c|}
\hline Fiber species & No. & Aspect ratio & Equivalent diameter $(\mathrm{mm})$ & Fiber type & Density $\left(\mathrm{g} / \mathrm{cm}^{3}\right)$ & Tensile strength $(\mathrm{MPa})$ \\
\hline \multirow{3}{*}{ Steel fiber } & SA & 30 & & & & \\
\hline & $\mathrm{SB}$ & 60 & 0.55 & Corrugated type & 7.8 & $\geq 600$ \\
\hline & SC & 80 & & & & \\
\hline \multirow{3}{*}{ Polypropylene fiber } & PA & 167 & & & & \\
\hline & PB & 280 & 0.048 & Monofilament type & 0.91 & $\geq 400$ \\
\hline & $\mathrm{PC}$ & 396 & & & & \\
\hline
\end{tabular}

$13.6 \mathrm{~mm}$, and $19 \mathrm{~mm}$, corresponding to the aspect ratios of 167,280 , and 396, respectively.

All the specimens were fabricated following the Chinese Standard CSCE 38:2004 [42]. After a uniform mix, the concrete was cast into plastic forms. After 24 hours, the specimens were demoulded carefully and stored in a standard curing room with a constant temperature of $20^{\circ} \mathrm{Cand}$ humidity of $95 \%$ until the 28 -day strength was achieved. Then the specimens were removed from the curing room, and the surfaces were cleaned with water. In addition, for each mixture, six cubes of $150 \mathrm{~mm}$ side length were prepared for compressive strength $\left(f_{\mathrm{cu}}\right)$ and splitting tensile strength $\left(f_{\text {st }}\right)$ tests. The test results from averaging a group of three are listed in Table 3.

2.2. Test Setup. The cyclic tests were performed on a universal electrohydraulic servo-rock testing machineINSTRON-1346 with a $2000 \mathrm{kN}$ load capacity, as shown in Figure 3. One linear variable displacement transducer (1\#LVDT) with a maximal range of $5 \mathrm{~mm}$ was used to measure the vertical displacement, and the lateral displacements were monitored by 2\#, 3\#LVDT during the loading process. The axial loads and displacements were automatically recorded to the data acquisition system with a synchronized frequency of $50 \mathrm{~Hz}$. The test setup is schematically shown in Figure 3.

2.3. Loading Scheme. A preload of approximately $10 \%$ of the ultimate strength was applied at the beginning of each test. A hierarchical loading method with a controlled displacement load was used, as shown in Figure 4. In the prepeak region (stageI), the displacement increment in each step was $0.15 \mathrm{~mm}$ with a loading speed of $0.01 \mathrm{~mm} / \mathrm{s}$. In the postpeak region (stage II), the displacement increment was then set to $0.3 \mathrm{~mm}$. The load-controlled method with a speed of $10 \mathrm{kN} / \mathrm{s}$ was used in the unloading process.

\section{Experimental Results}

3.1. Failure Pattern. Figure 5 shows the typical failure modes of concrete specimens. It is found that there are distinct differences in the failure modes between plain concrete and FRC. The failure of FRC is dominated by shear cracks, whilst that of plain concrete is determined by tensile cracks. For plain concrete (S000P000), the concrete specimen collapses into fine columns sharing the axial load at the end of loading process. Nearly vertical macrocracks that coalesced from microcracks and initial defects can be observed. In
TABLE 3: Details of specimens.

\begin{tabular}{lccccccc}
\hline \multirow{2}{*}{ No. } & Specimens & \multicolumn{2}{c}{ SF } & \multicolumn{2}{c}{ PF } & $f_{\mathrm{cu}}$ & $f_{\mathrm{st}}$ \\
& & $V_{\mathrm{sf}}$ & $l_{\mathrm{sf}} / d_{\mathrm{sf}}$ & $V_{\mathrm{pf}}$ & $l_{\mathrm{pf}} / d_{\mathrm{pf}}$ & $(\mathrm{MPa})$ & $(\mathrm{MPa})$ \\
\hline 1 & S000P000 & - & - & - & - & 47.53 & 2.75 \\
2 & SB10P000 & $1.00 \%$ & 60 & - & - & 51.75 & 3.96 \\
3 & SB15P000 & $1.50 \%$ & 60 & - & - & 52.91 & 4.47 \\
4 & S000PA15 & - & - & $0.15 \%$ & 167 & 48.80 & 3.47 \\
5 & S000PC15 & - & - & $0.15 \%$ & 396 & 50.65 & 3.58 \\
6 & SB10PA10 & $1.00 \%$ & 60 & $0.10 \%$ & 167 & 53.71 & 3.99 \\
7 & SB10PA15 & $1.00 \%$ & 60 & $0.15 \%$ & 167 & 55.2 & 4.13 \\
8 & SB15PA10 & $1.50 \%$ & 60 & $0.10 \%$ & 167 & 58.05 & 4.61 \\
9 & SA15PB15 & $1.50 \%$ & 30 & $0.15 \%$ & 280 & 54.65 & 4.19 \\
10 & SB15PA15 & $1.50 \%$ & 60 & $0.15 \%$ & 167 & 53.35 & 4.25 \\
11 & SB15PB15 & $1.50 \%$ & 60 & $0.15 \%$ & 280 & 52.35 & 4.36 \\
12 & SB15PC15 & $1.50 \%$ & 60 & $0.15 \%$ & 396 & 51.15 & 4.50 \\
13 & SC15PA15 & $1.50 \%$ & 80 & $0.15 \%$ & 167 & 53.70 & 4.76 \\
14 & SB15PA20 & $1.50 \%$ & 60 & $0.20 \%$ & 167 & 50.91 & 3.76 \\
15 & SB20PA15 & $2.00 \%$ & 60 & $0.15 \%$ & 167 & 56.22 & 5.36 \\
16 & SB20PA20 & $2.00 \%$ & 60 & $0.20 \%$ & 167 & 54.65 & 5.07 \\
\hline
\end{tabular}

comparison with plain concrete, diagonal cracks with an angle ranging from $45^{\circ}$ to $60^{\circ}$ can be seen obviously in FRC specimens. For polypropylene fiber-reinforced concrete (PFRC), the specimens demonstrate a brittle failure pattern, indicating that $\mathrm{PF}$ induces sudden energy dissipation due to fiber-fracturing events. For SFRC, the cracks are finer and smaller than those of plain concrete, which is mainly owing to the fiber crack-arresting effect. Moreover, it is evidenced that BFRC specimen behaves more ductile, with better specimen integrity.

3.2. Cyclic Stress-Strain Response. The typical axial stressstrain relations of BFRC for various fiber volume fractions and aspect ratios under cyclic compression are illustrated in Figure 6. The cyclic stress-strain responses can be summarized as follows:

(i) Distinct Unloading and Reloading Paths. A full cycle of the stress-strain response is composed of two distinct and well-defined paths: unloading branch and reloading branch. The unloading branch typically exhibits a curvilinear feature that is characterized by a progressive slope reduction. The path eventually intersects the horizontal strain axis with an unrecoverable strain that is referred to as plastic strain. Immediately after, the reloading path is approximately linear until the intersection with unloading path, which is followed by a significant nonlinearity once the unloading strain, is exceeded. 


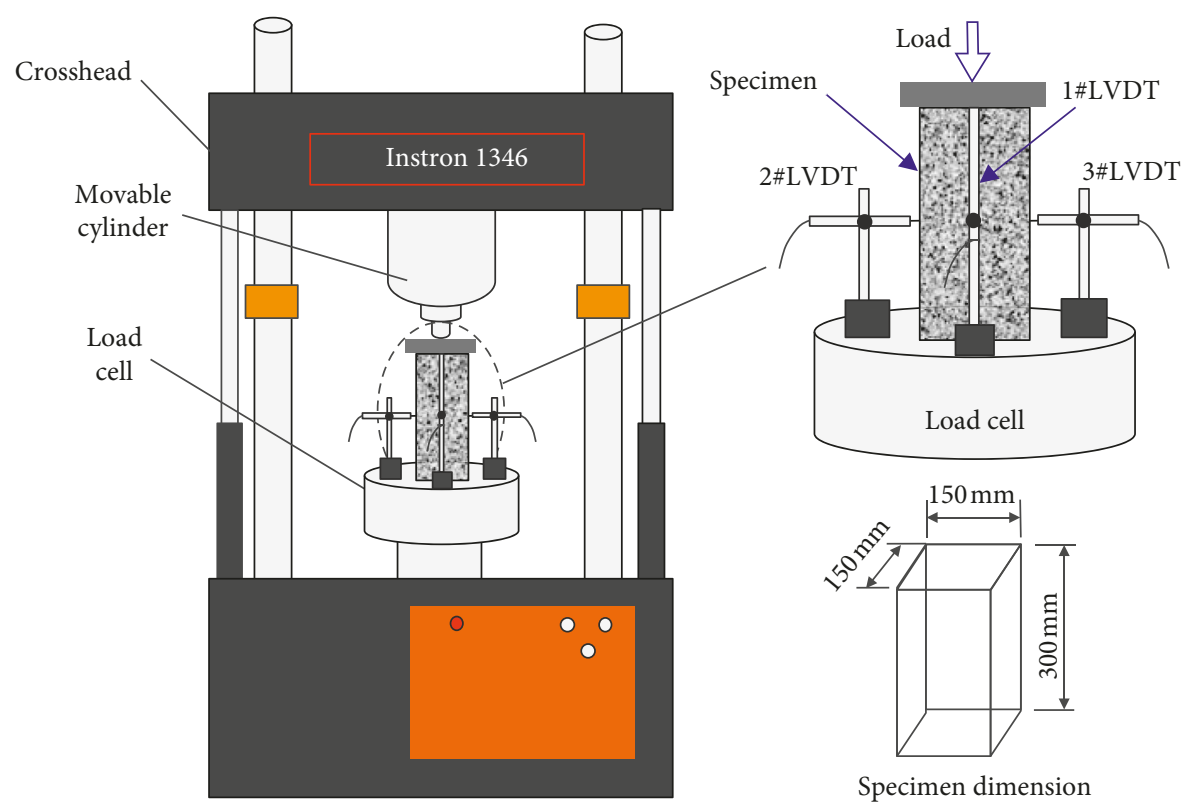

FIgURE 3: Schematic diagram of experimental setups.

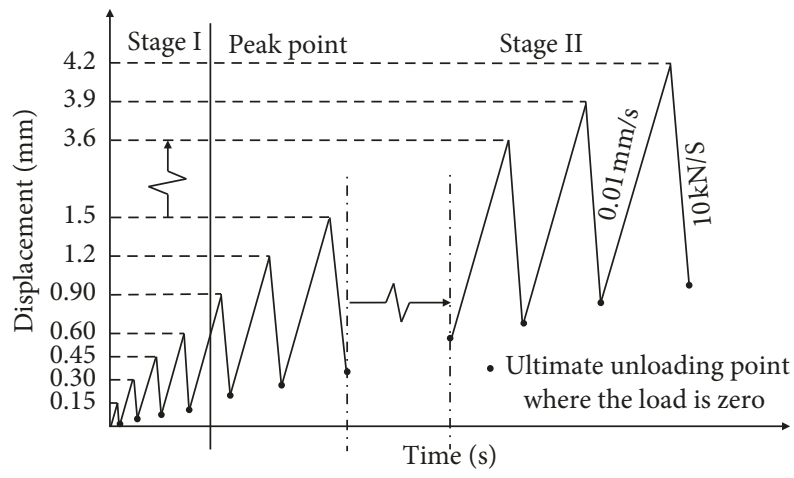

FIGURE 4: Schematic diagram of cyclic loading procedure [37].

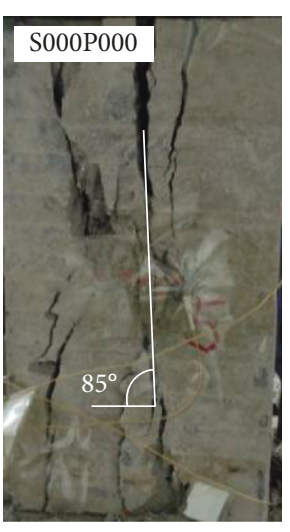

(a)

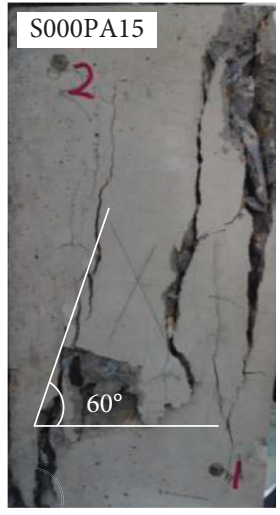

(b)

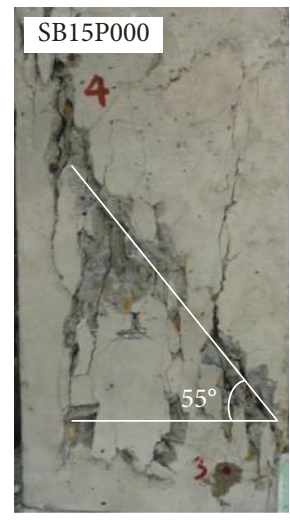

(c)

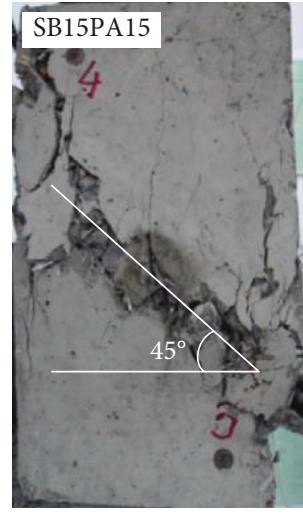

(d)

FIgURE 5: Typical failure modes for concrete specimens.

(ii) Remarkable Performance Degradation. Remarkable degradation in elastic stiffness and stress can be observed for all the stress-strain curves, which differ widely for different fiber parameters. The initial segment for each unloading path is almost vertical with an abrupt stress drop for a small strain change; 

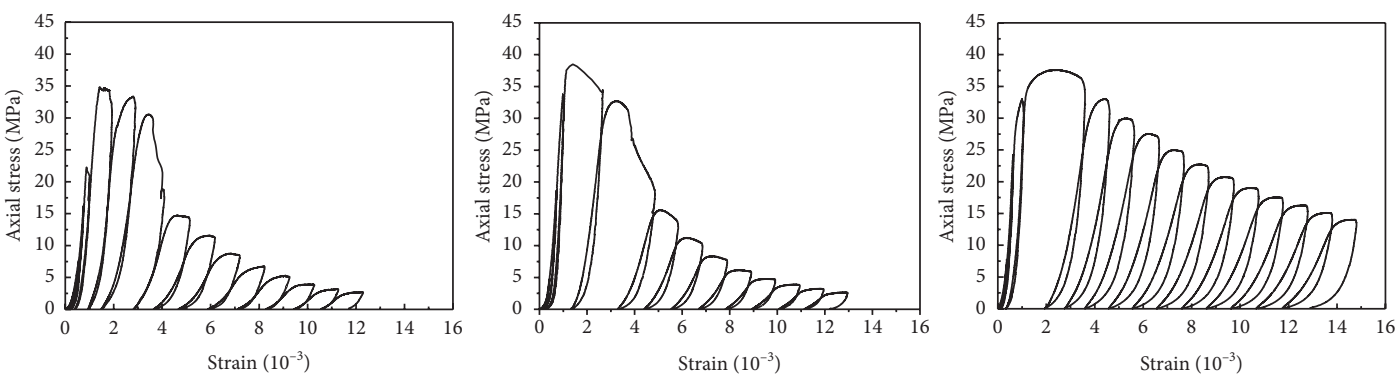

— S000P000

(a)
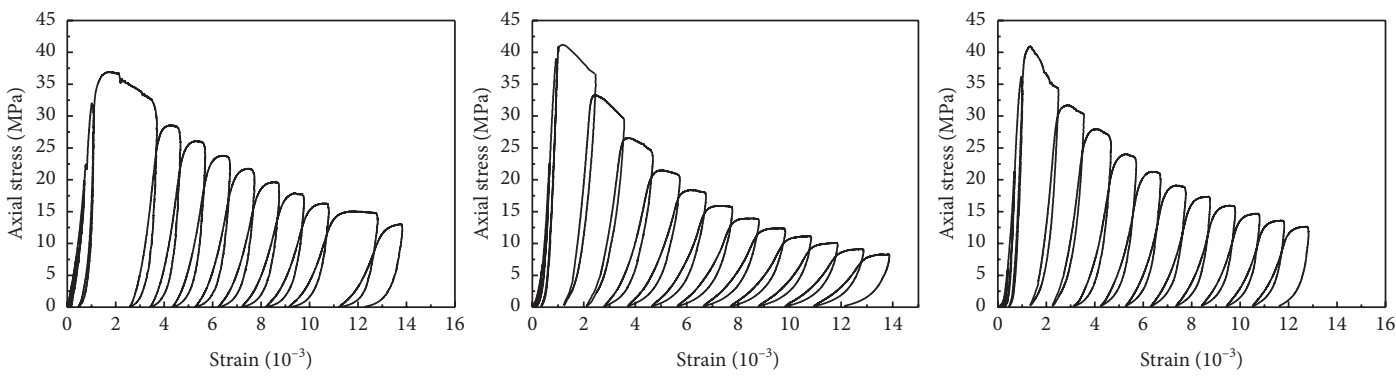

— SB10PA15

— SB15PA15

- SB20PA15

(b)

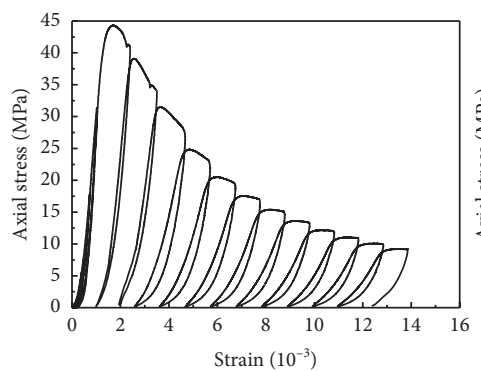

— SA15PA15

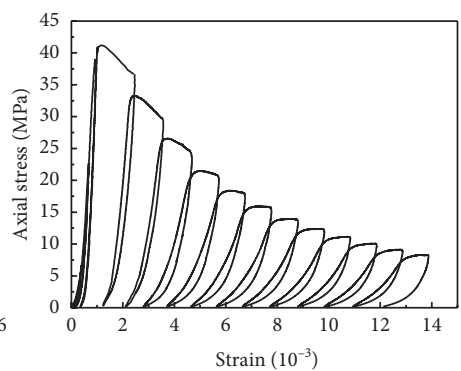

— SB15PA15

(c)

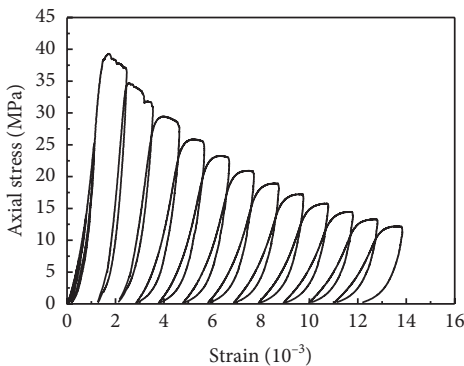

— SB15PA10

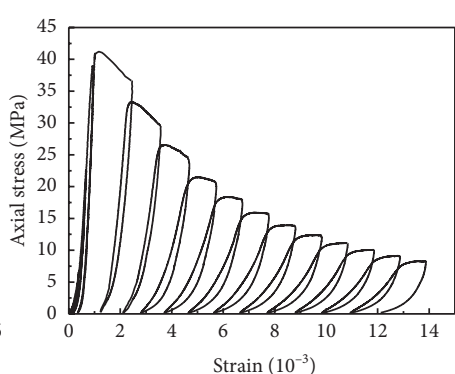

— SB15PA15

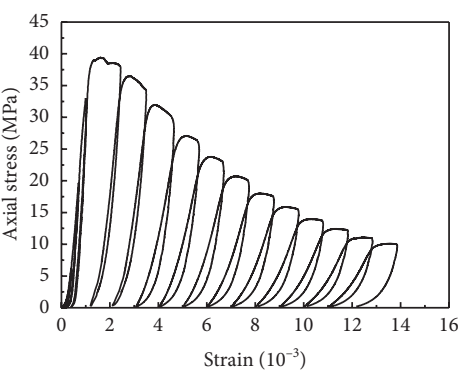

— SC15PA15

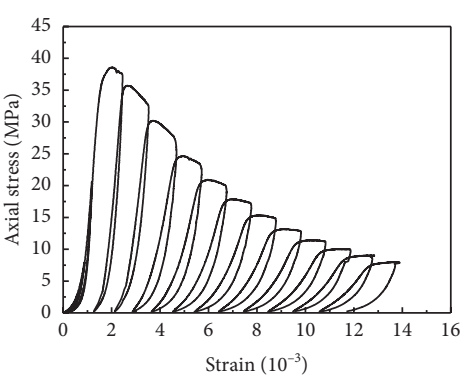

— SB15PA20

(d)

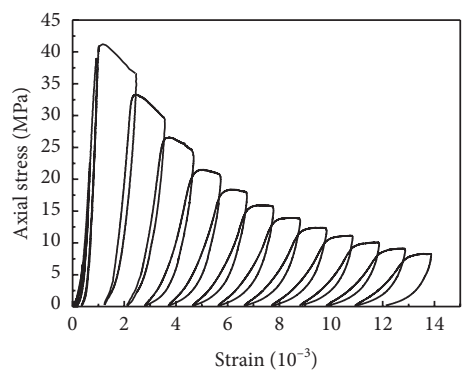

— SB15PA15

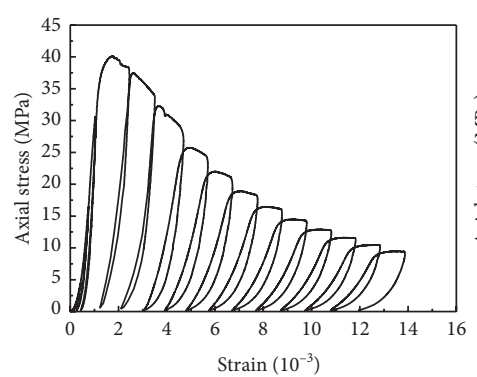

— SB15PB15

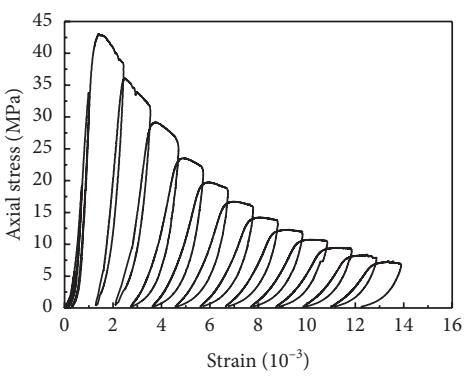

— SB15PC15

(e)

FIGURE 6: Cyclic stress-strain relations of BFRC specimen for various fiber volume fractions and aspect ratios. (a) Effect of fiber types. (b) Effect of volume fraction of SF. (c) Effect of aspect ratio of SF. (d) Effect of volume fraction of PF. (e) Effect of aspect ratio of PF. 
however, when approaching the strain axis, the curvature of the unloading path turns larger. It is noted that in comparison with the envelope stress at the same unloading strain, significant stress deterioration can be observed after unloading and reloading, which is caused by the crack propagation and damage accumulation.

(iii) Hysteretic Energy Dissipation Capacity. Prior to the peak strength, the unloading path is almost overlapping with the loading path because the concrete specimen almost remains elastic, where the hysteretic energy dissipation is not evident. However, in the postpeak region, the hysteretic loop becomes more obvious with increasing loading cycles. In addition, the capacity of FRC in hysteretic energy dissipation is stronger than that of plain concrete, and for plain concrete, a small hysteretic loop after the peak stress is observed, and it fades away with increasing loading cycles. The phenomenon is attributed to the debonding between aggregate and cement matrix in plain concrete, and the interfacial cracks propagate along with the principle macrocracks. With respect to SFRC, the energy dissipation remains active. At the failure stage, fiber sliding and pull-out mechanism are the main contributors to energy dissipation.

(iv) Envelope Curve. In general, the stress-strain envelope curves of FRC are smoother than those of plain concrete. For plain concrete, a sharp load drop after the peak point due to damage accumulation can be observed. For FRC, the load drop is slighter than that of plain concrete owing to fiber crack-bridging effect, especially for SFRC and BFRC. Furthermore, a slower rate of elastic stiffness degradation is observed for SFRC specimens, which is consistent with the conclusions in the literature $[34,37]$.

Figure 7 depicts a schematic diagram of a cyclic stressstrain curve extracted from the current results, which is believed to be well suited to reproduce the actual cyclic compressive response. The corresponding morphologies of typical specimen surfaces for each loading stage are also shown in Figure 7. It can be observed from the test results that the cyclic compressive process can be divided into six stages:

(i) Elastic stage (Path OA). The initial microcracks are restrained by the randomly distributed fibers. The contributions of blended fiber on the mechanical behavior of BFRC at this stage are negligible.

(ii) Initial crack propagating stage (Path $\mathrm{AB}$ ). Visible fine cracks can be observed on the specimen at this stage. The internal crack distributions and the degree of crack propagation are determined by the volume fraction of PF [10].

(iii) Stable crack propagating stage (Path BC). Macrocracks can be seen when the load reaches the ultimate strength, and at the peak stress, a sudden increase in the width of cracks can be observed, which is induced by the events of steel fiber pull-out, matrix cracking, and debonding between the aggregate and matrix.

(iv) Fracture-occurring stage (Path CD). The cracks in specimens propagate and coalesce into a main crack. The deformation of PF increases continuously or PF fractures. At this stage, steel fiber debonding occurs continuously with increasing loads and loading cycles.

(v) Continuous failure stage (Path DE). The width of the main cracks becomes larger, and the partial SFs are completely pulled out, with small pieces of concrete peeled off.

(vi) Convergence stage (Path EF). The tensile stress between the two sides of a crack is undertaken by SFs, and when the increasing amount of fibers is pulled out, the concrete specimen collapses into failure.

In addition, Path GH is the unloading stage, where the stress is diminishing and the elastic deformation is recovered, with partial cracks closure. Path $\mathrm{HI}$ is the first reloading stage. The axial stress has not reached the last unloading stress, and therefore, the width of cracks almost remains as a constant. Path IJ is the second reloading stage. At this stage, the cracks propagate continually until the next unloading strain.

\section{Analysis and Discussion}

4.1. Envelope Curve. In order to analyze the effects of blended fiber on the mechanical behavior of concrete, the envelope curves referenced as the upper boundary of a cyclic response are plotted for each specimen, as shown in Figure 8. The results indicate that the fibers mainly affect the postpeak response of concrete; the envelope curves in the prepeak region for different fiber parameters are almost identical with the lone exception of peak strength. Figures 8(a) and 8(b) show that when adding SF into concrete matrix, an enhancement in peak stress is observed, and the degradations in concrete mechanical properties in terms of strength and initial elastic stiffness are slighter than those of PFRC specimens (S000PA15). The peak strength of concrete increases with an increase in the fiber volume fraction and decreases with increasing fiber aspect ratio. In addition, the effect of SF on the ductile behavior has a certain fluctuation under cyclic loads. With respect to PF, it can be observed from Figures 8 (c) and 8 (d) that the addition of PF has a slight improvement on the peak strength of BFRC specimens; however, the degradation in strength is much more significant than that of SFRC specimens (SB15P000).

Based on the above descriptions, it can be concluded that the synergistic effect of blended fiber is positive on the concrete strength, despite that the effect of PF has a small fluctuation. However, adding PF into concrete matrix has insignificant effects on the ductility of concrete specimens 

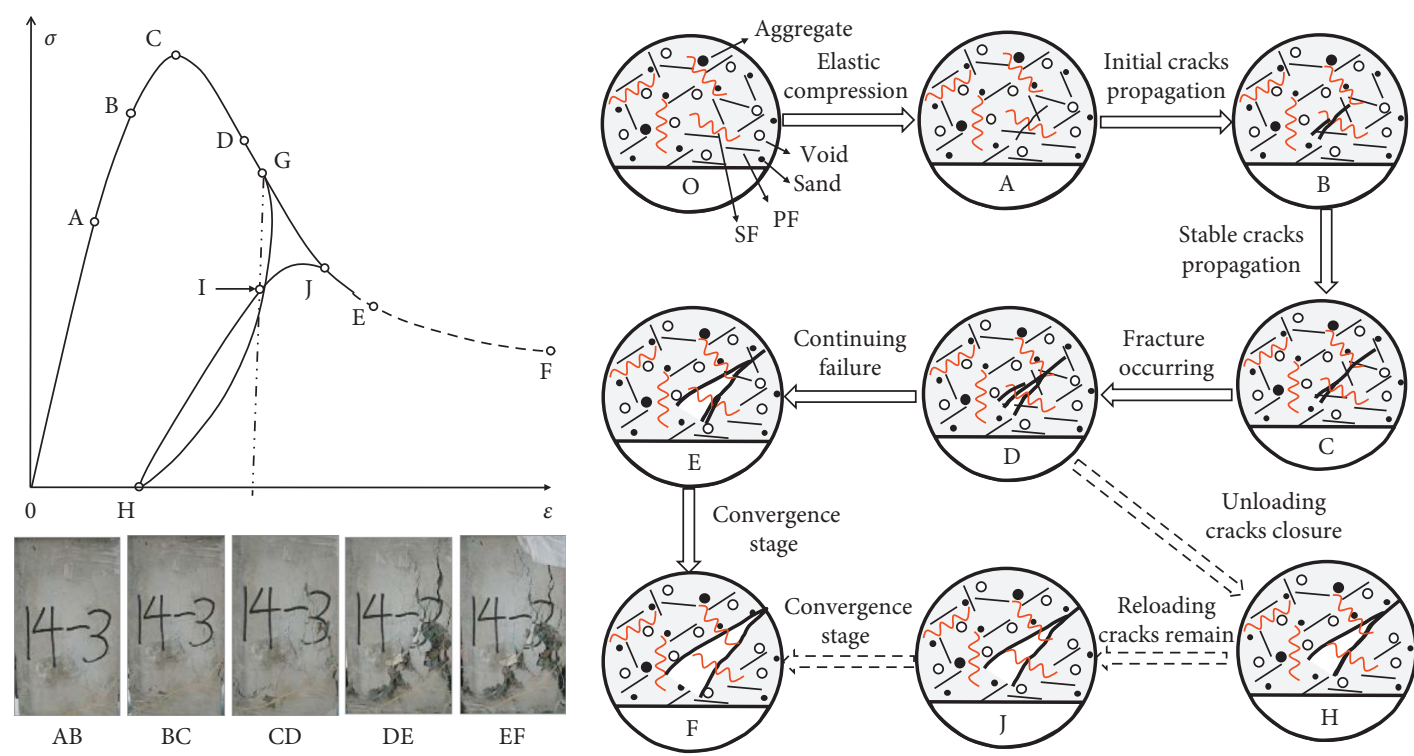

(b)

(a)

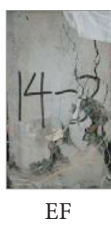

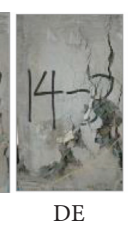

FIgURE 7: Ideal schematic of cyclic compressive process of BFRC specimen. (a) Schematic of stress-strain curve and the corresponding morphologies of typical specimen surface for each loading stage. (b) The schematic drawing showing propagation of a crack.

when subjected to cyclic loading in this study, which can be interpreted that initial damages such as microcracks and weak interfaces increase with increasing volume fraction of PF.

4.2. Plastic Strain. The plastic strain is the accumulated residual axial strain of concrete when the load is unloaded to zero [37]. At present, various formulae for the relationship between plastic strain and envelope unloading strain in the literature have been proposed [18-20]. In this work, from a regression analysis, the power function $\left(y=p x^{q}\right)$ proposed by Bahn and Hsu [18] is used, where the parameter $p$ is a coefficient of plastic strain and the parameter $q$ is an optimum order which controls the curvature of the relationship curve. Figure 9 shows the relations of plastic strain $\left(\varepsilon_{\mathrm{pl}}\right)$ and envelope unloading strain $\left(\varepsilon_{\mathrm{unl}}\right)$ of BFRC specimens for different fiber volume fractions and aspect ratios subjected to uniaxial cyclic compression. The best fitting parameters are listed in Table 4 . The comparisons of parameter $p$ between the fitting and predicted results are shown in Figure 9(f).

It is seen from Figure 9(a) that the plastic strain of FRC specimen is smaller than that of plain concrete at the same envelope unloading strain. It can be interpreted that fibers can bridge microcracks that induce permanent strain due to crack propagation and damage accumulation. Moreover, the crack-arresting capacity of PF is smaller than that of SF. In addition, in most cases, as the fiber volume fraction (for both PF and SF) increases (see in Figures 9(b) and 9(d)), the plastic strain of BFRC specimen decreases in comparison with SFRC and PFRC. Despite that the effect of fiber aspect ratio is fluctuating, all the plastic strains of BFRC are smaller than SFRC and PFRC (see in Table 4), resulted in a notable synergistic effect.
The above analysis could be explained by the effective fiber bridging effect of fiber reinforcing index, which is proportional to the fiber volume fraction and aspect ratio [39]. The format of fiber characteristic parameter $\lambda_{\text {sf }}$ can be given as follows:

$$
\lambda_{\mathrm{f}}=\frac{V_{\mathrm{f}} l_{\mathrm{f}}}{d_{\mathrm{f}}} .
$$

In this work, two reinforcing indexes $\eta_{1}$ and $\eta_{2}$ are introduced, which are functions of fiber characteristic parameters. However, due to the lack of research on the synergetic effect of blended fibers on the concrete performance, the positive synergetic effect is neglected in this study. Conservatively, the contributions of blended fiber are only numerically superimposed, i.e., the factor $\eta_{i}$ is defined as follows:

$$
\eta_{i}=1+\alpha_{i} \lambda_{\mathrm{sf}}+\beta_{i} \lambda_{\mathrm{pf}}
$$

Thus, the fitting parameters $p, q$ can be expressed as $p=a_{0} \eta_{1}, q=b_{0} \eta_{2}$, where $p_{0}$ and $q_{0}$ are the fitting parameters for plain concrete. Based on the least-squares analysis, rounded coefficients $\alpha_{1}=-0.111, \quad \beta_{1}=-0.281$ and $\alpha_{2}=-0.07, \beta_{2}=0.08$ are suggested to evaluate the contributions of SF and PF for the reinforcing indexes $\eta_{1}$ and $\eta_{2}$, with the goodness of fit being 0.978 and 0.998 , respectively. However, because the effects of fibers on the shapes of the curve are insignificant, the influences can be ignored [3337]. Herein, $q=1.276$ is suggested in this paper. The analytical formula of $p$ is shown as follows:

$$
p=0.589\left(1-0.111 \lambda_{\mathrm{sf}}-0.281 \lambda_{\mathrm{pf}}\right)
$$

Figure 9(f) illustrates the comparisons of the predicted and experimental fitting results for the coefficient $a$. It is observed that a reasonable agreement is obtained. Therefore, 


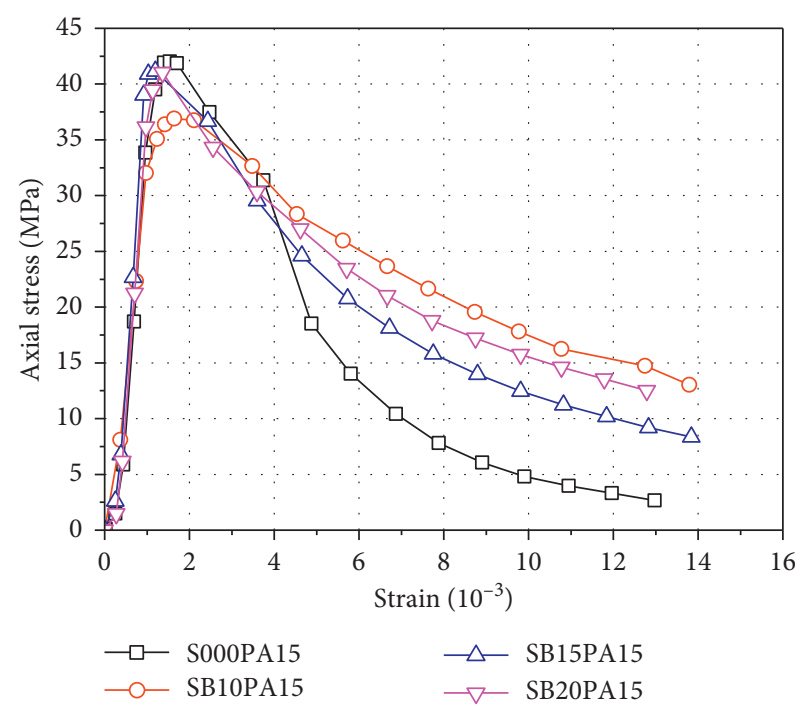

(a)

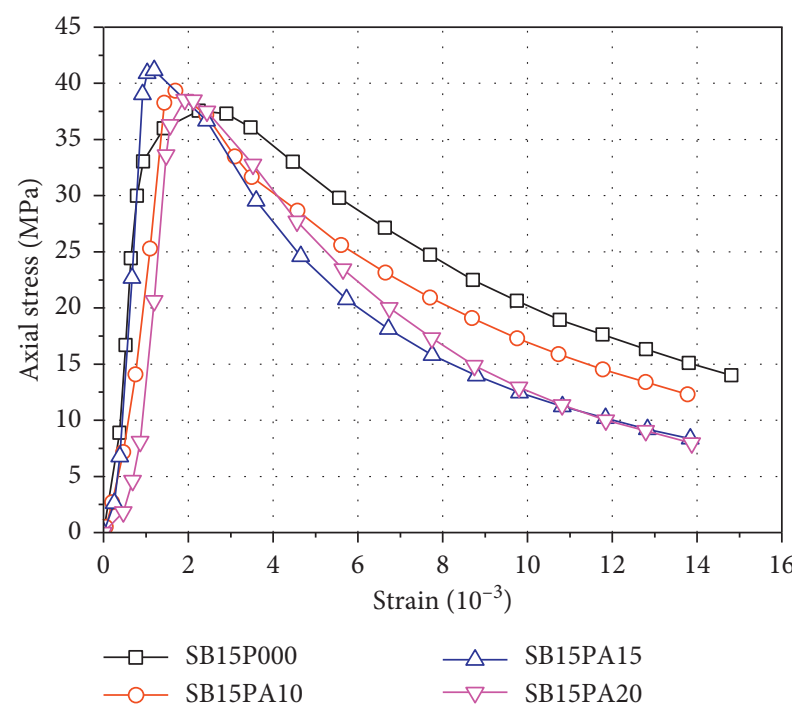

(c)
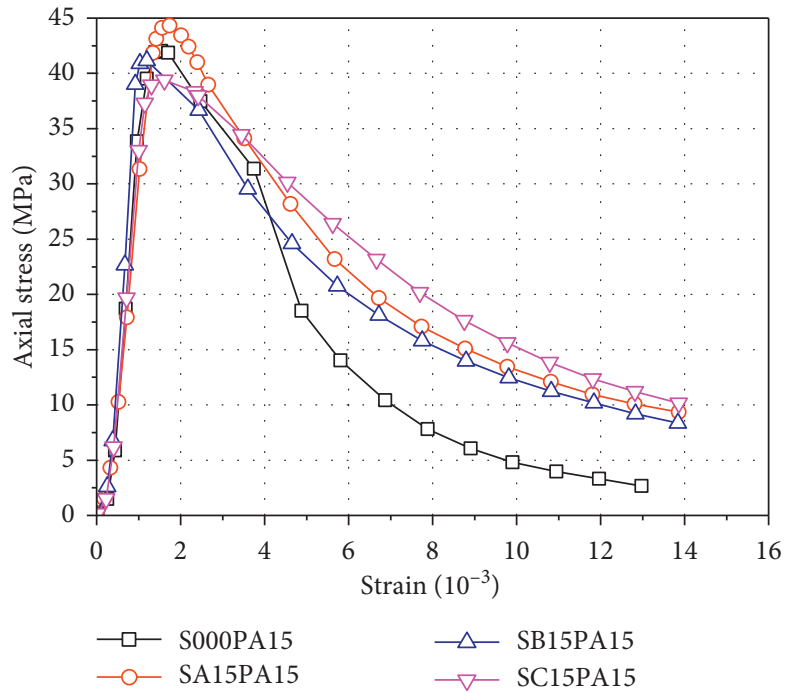

(b)

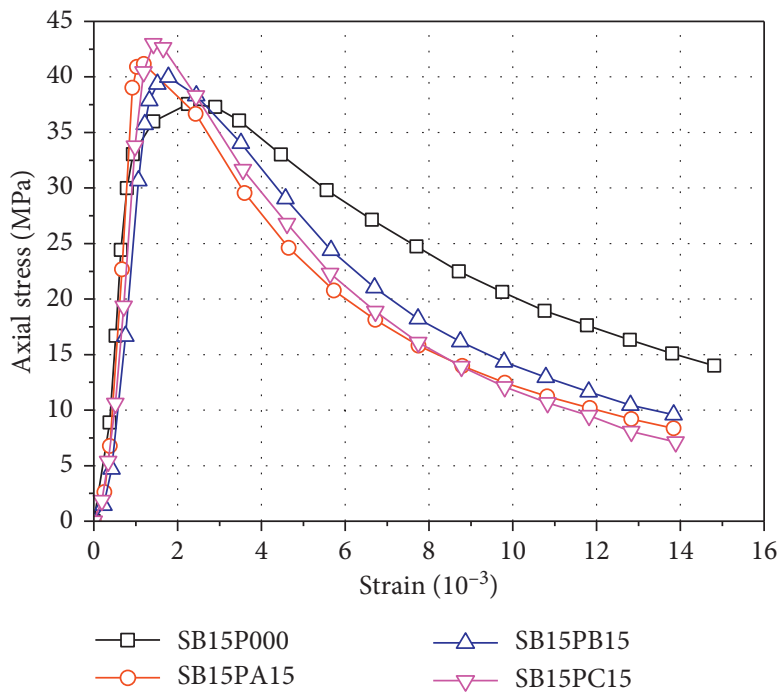

(d)

FIGURE 8: Envelope curves of BFRC specimens for different fiber volume fractions and aspect ratios. (a) Effect of volume fraction of SF. (b) Effect of aspect ratio of SF. (c) Effect of volume fraction of PF. (d) Effect of aspect ratio of PF.

the relation between the plastic strain ratio $\varepsilon_{\mathrm{pl}} / \varepsilon_{\mathrm{cu}}$ and envelope unloading strain ratio $\varepsilon_{\mathrm{unl}} / \varepsilon_{\mathrm{cu}}$ is expressed as follows:

$$
\frac{\varepsilon_{\mathrm{pl}}}{\varepsilon_{\mathrm{cu}}}=0.589\left(1-0.111 \lambda_{\mathrm{sf}}-0.281 \lambda_{\mathrm{pf}}\right)\left(\frac{\varepsilon_{\mathrm{unl}}}{\varepsilon_{\mathrm{cu}}}\right)^{1.276} \text {. }
$$

4.3. Elastic Stiffness Degradation. Elastic stiffness degradation is a key aspect to reflect the damage evolution, which can be quantified by the variations of elastic reloading modulus during cyclic loading. In the present study, as a simplified calculation rule, the slope between the unloading point and ultimate unloading point is defined as the unloading elastic modulus, as shown in Figure 10. The calculated elastic stiffness values of each cycle as well as the initial modulus of the undamaged material $E_{0}$ are listed in Table 5.
Figure 11 shows the elastic stiffness degradation process with increasing unloading strain for BFRC specimens. Distinct elastic stiffness degradation with increasing loading cycles can be observed from Figure 11(f). In general, the process can be divided into two stages: descending stage and stable stage. At the descending stage, an obvious drop in the unloading modulus can be observed. The elastic stiffness ratio $\left(E_{\mathrm{unl}, i} / E_{0}\right)$ decreases with increasing unloading strain which may due to initial defect propagation as the loads and loading cycles increased. The microcracks fall into macrocracks, and the damages in specimens accumulate gradually. Thereafter, the elastic modulus of a specimen almost remains constant until the concrete specimen collapses into failure.

In comparison with plain concrete, the elastic stiffness degradation of FRC is moderate. The stiffness ratios of FRC are larger than that of plain concrete (see in Figure 11(a)). 

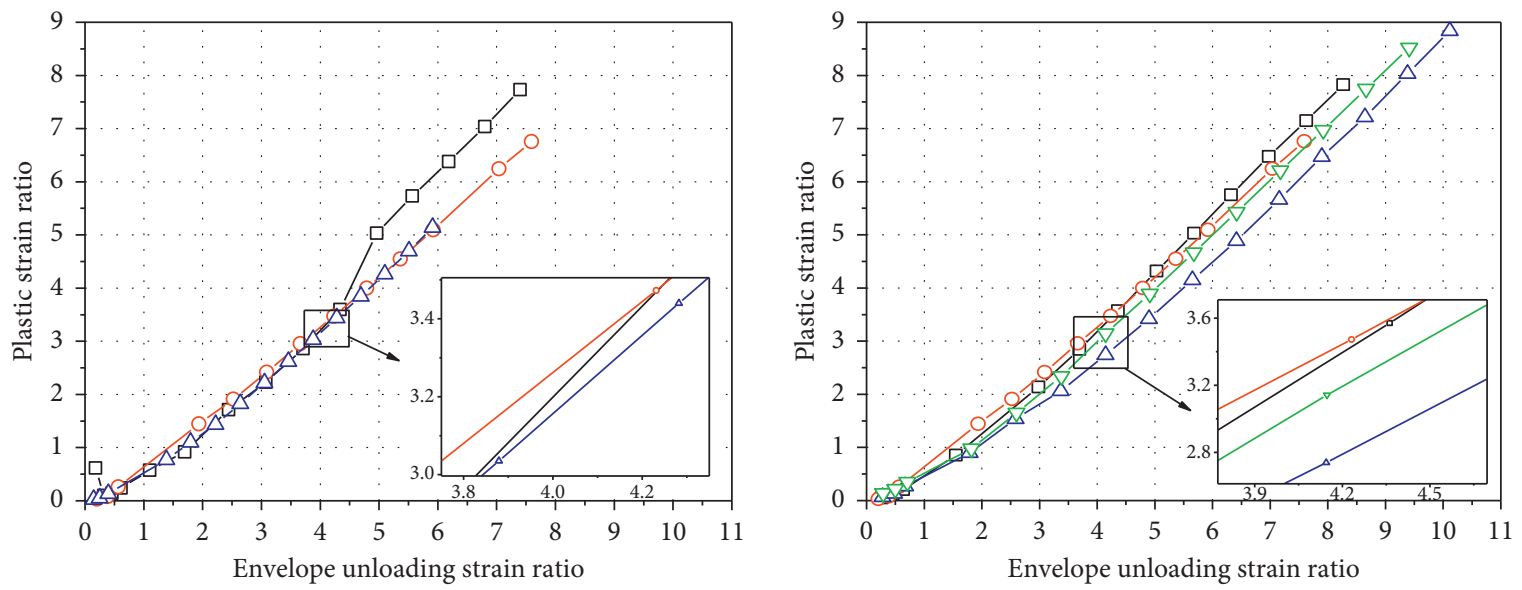

$-\square-$ S000P000
$-O-$ S000PA15

$-\square-$ S000PA15 $\quad-\triangle-$ SB15PA15

$-O-$ SB10PA15 $\quad-\nabla-$ SB20PA15

(a)

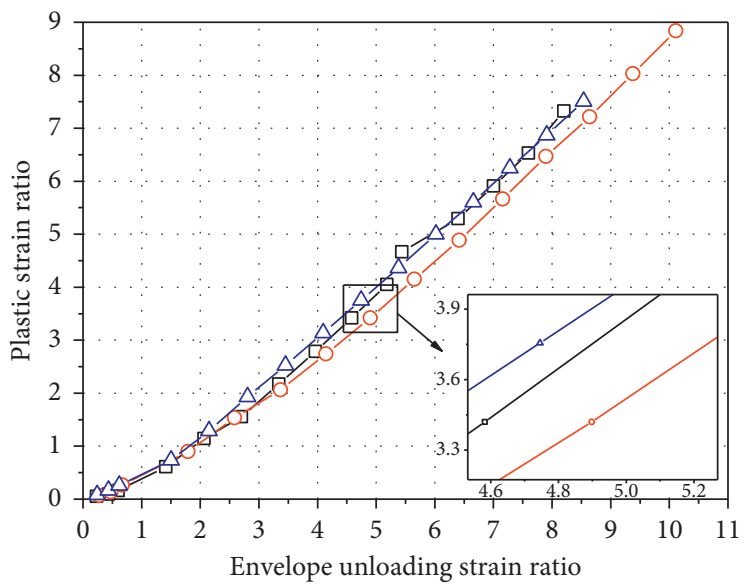

- - SA15PA15

- - - SB15PA15

$-\triangle-$ SC15PA15

(c)

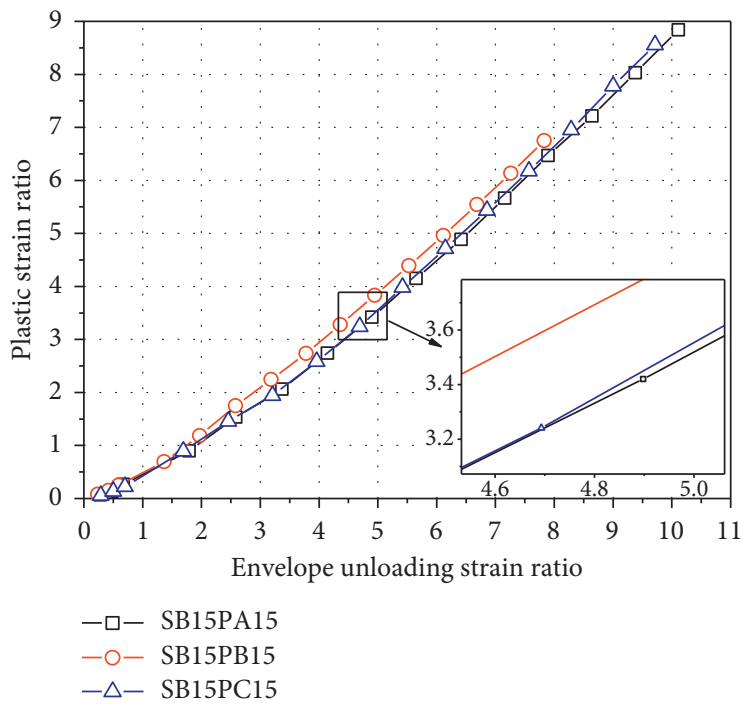

(e) (b)

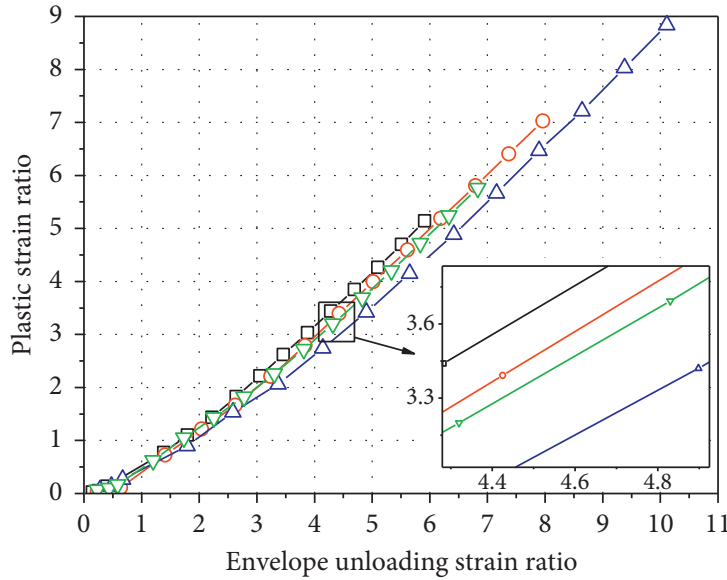

(d)

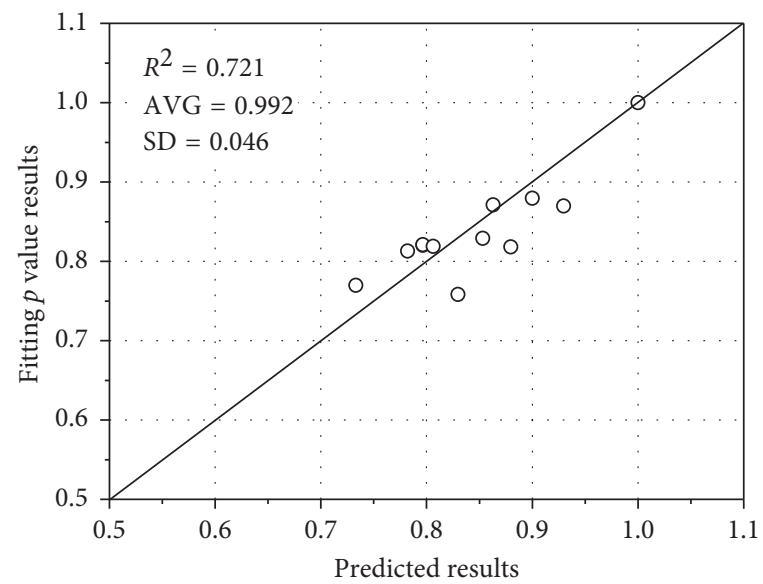

(f)

FIGURE 9: Relations between plastic strain and envelope unloading strain. (a) Effect of fiber type. (b) Effect of volume fraction of SF. (c) Effect of aspect ratio of SF. (d) Effect of volume fraction of PF. (e) Effect of aspect ratio of PF. (f) Comparisons of plastic strain between fitting and predicted results. 
TABLE 4: Fitting parameters for the relation between plastic strain and envelope unloading strain.

\begin{tabular}{lcccc}
\hline Specimens & $\lambda_{\text {sf }}$ & $\lambda_{\mathrm{pf}}$ & $a$ & $R_{t}^{a}$ \\
\hline S000P000 & 0.00 & 0.000 & 0.589 & 1.000 \\
S000PA15 & 0.00 & 0.251 & 0.527 & 0.870 \\
SB15P000 & 0.90 & 0.000 & 0.533 & 0.880 \\
SB10PA15 & 0.60 & 0.251 & 0.528 & 0.871 \\
SB15PA15 & 0.90 & 0.251 & 0.459 & 0.758 \\
SB20PA15 & 1.20 & 0.251 & 0.497 & 0.820 \\
SA15PA15 & 0.45 & 0.251 & 0.496 & 0.818 \\
SC15PA15 & 1.20 & 0.251 & 0.497 & 0.821 \\
SB15PA10 & 0.90 & 0.167 & 0.502 & 0.829 \\
SB15PA20 & 0.90 & 0.334 & 0.496 & 0.819 \\
SB15PB15 & 0.90 & 0.420 & 0.493 & 0.813 \\
SB15PC15 & 0.90 & 0.594 & 0.467 & 0.770 \\
\hline
\end{tabular}

Note: $a$ is the basic characteristic parameters of fitting results; $R_{t}^{a}$ represents the ratio of plastic strain fitting parameters related to that of the control concrete specimen.

A sharp drop in elastic stiffness of plain concrete specimen is observed when the load reaches the peak strength, while that of FRC specimen is smoother [37]. The results indicate that fibers can effectively alleviate the speed of elastic stiffness degradation, especially for SF. Moreover, for plain concrete, the specimens are sliced into small columns sharing the axial load at the end of loading process, with the stiffness ratio below 0.03 . While for FRC, the stiffness ratio is higher than 0.06 accounted for that the loads are carried by both fibers and concrete. With respect to the effects of fiber volume fraction (see in Figures 11(b) and 11(d)), an increase in the volume fraction of SF induces an increase in the elastic stiffness ratio, while an opposite trend can be observed as the volume fraction of PF increased. In terms of fiber aspect ratio, the influences on elastic stiffness degradation are insignificant (see in Figures 11(c) and 11(e)).

4.4. Stress Deterioration. Research results on the stress deterioration of uniaxial cyclic compression have shown that the stress of a reloading branch is less than the envelope unloading stress at the same unloading strain [14-20]. In this work, a parameter $\varphi$ is introduced to quantify the stress deterioration ratio [43] shown in Figure 10 and defined as the following:

$$
\varphi=\frac{\sigma_{\mathrm{re}}}{\sigma_{\mathrm{unl}}},
$$

where $\sigma_{\mathrm{re}}$ is the stress on the reloading path at a strain level equal to the envelope unloading strain $\left(\varepsilon_{\text {unl }}\right)$.

The relations between the stress deterioration ratio and nondimensionalized envelope unloading strain $\left(\varepsilon_{\mathrm{c}} / \varepsilon_{\mathrm{cu}}\right)$ are shown in Figure 12. The results indicate that the stress deterioration ratio accesses to 1.0 when the matrix is still elastic. A sharp drop in the stress deterioration ratio is followed when the load reaches the ultimate strength. Thereafter, the stress deterioration ratio remains stable in the subsequent loading cycles.

With respect to the fiber effects, the results indicate that the influences are insignificant, especially when the

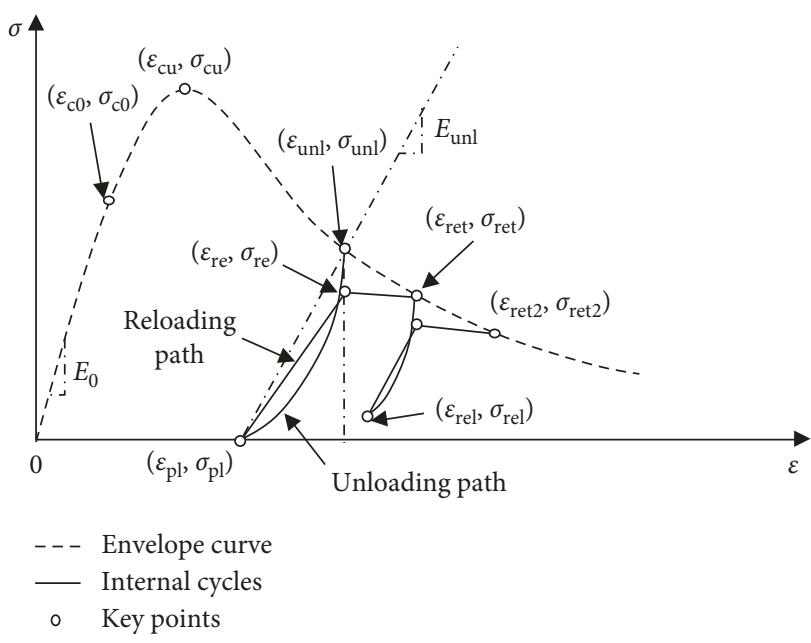

FIgURE 10: Key parameters' definition of cyclic stress-strain of BFRC.

nondimensionalized unloading strain exceeds 3.0. However, a fluctuant fiber effect can still be seen when the nondimensionalized unloading strain is less than 3.0, which can be ignored according to the conclusions in the literature [25-28]. In this study, based on the analysis of test results, a critical point where $\varepsilon_{\mathrm{unl}} / \varepsilon_{\mathrm{cu}}=3$ is postulated, and the constant coefficient 0.85 is obtained for the stress deterioration ratio at the stable stage. For simplicity, the following model for stress deterioration process is proposed, as shown in Figure 13 (black straight line) and expressed as the following:

$$
\begin{aligned}
& \varphi=1-0.05 \frac{\varepsilon_{\mathrm{unl}}}{\varepsilon_{\mathrm{cu}}} \quad 0<\frac{\varepsilon_{\mathrm{unl}}}{\varepsilon_{\mathrm{un}}}<3, \\
& \varphi=0.85 \quad \frac{\varepsilon_{\mathrm{unl}}}{\varepsilon_{\mathrm{un}}}>3 .
\end{aligned}
$$

\section{Cyclic Constitutive Model}

This section presents a cyclic constitutive model for BFRC based on the experimental results in the current study. The proposed model consists of three components: (1) a monotonic stress-strain model to describe the envelope curve, (2) a power expression for the unloading path, and (3) a broken line for the reloading path, as shown in Figure 10. The key parameters of the cyclic constitutive model are defined in Figure 10.

5.1. Cyclic Envelope Curve. Previous experimental studies have shown that the monotonic stress-strain curve can be generally assumed as the envelope curve of concrete material under cyclic compression [13-19, 21-27]. The model, initially proposed by Guo and Zhang [44], is further developed and amended that accounts for the presence of blended fiber. It involves a parabola consisting of a curvilinear ascending portion followed by a descending branch, as shown in the following equation. 
TABLE 5: Elastic stiffness versus unloading strain for concrete specimens.

\begin{tabular}{|c|c|c|c|c|c|c|c|c|c|c|c|}
\hline$\varepsilon_{\text {unl }}$ & $E_{\text {unl }}$ & $\varepsilon_{\text {unl }}$ & $E_{\text {unl }}$ & $\varepsilon_{\text {unl }}$ & $E_{\text {unl }}$ & $\varepsilon_{\text {unl }}$ & $E_{\text {unl }}$ & $\varepsilon_{\text {unl }}$ & $E_{\text {unl }}$ & $\varepsilon_{\text {unl }}$ & $E_{\text {unl }}$ \\
\hline \multicolumn{2}{|c|}{ SOOOP000 } & \multicolumn{2}{|c|}{ S000PA15 } & \multicolumn{2}{|c|}{ SB15P000 } & \multicolumn{2}{|c|}{ SB10PA15 } & \multicolumn{2}{|c|}{ SB15PA15 } & \multicolumn{2}{|c|}{ SB20PA15 } \\
\hline 0.00 & 53.86 & 0.00 & 71.35 & 0.00 & 67.62 & 0.00 & 75.34 & 0.00 & 75.06 & 0.00 & 84.00 \\
\hline 1.02 & 33.28 & 0.99 & 50.20 & 1.01 & 50.13 & 1.03 & 57.82 & 0.92 & 70.85 & 0.96 & 74.21 \\
\hline 1.82 & 22.70 & 2.43 & 34.50 & 3.46 & 20.60 & 3.51 & 36.46 & 2.46 & 29.99 & 2.48 & 29.92 \\
\hline 2.82 & 15.92 & 4.68 & 15.30 & 4.50 & 19.16 & 4.58 & 25.53 & 3.54 & 20.57 & 3.54 & 23.46 \\
\hline 4.05 & 8.51 & 5.79 & 10.49 & 5.54 & 15.57 & 5.61 & 21.26 & 4.62 & 13.71 & 4.60 & 19.02 \\
\hline 5.10 & 6.34 & 6.84 & 8.35 & 6.58 & 13.82 & 6.65 & 18.42 & 5.68 & 10.77 & 5.65 & 17.22 \\
\hline 6.15 & 4.54 & 7.88 & 7.00 & 7.62 & 12.35 & 7.68 & 15.59 & 6.72 & 8.86 & 6.69 & 15.15 \\
\hline 7.20 & 3.97 & 8.90 & 5.83 & 8.65 & 11.14 & 8.69 & 13.62 & 7.75 & 7.66 & 7.72 & 13.78 \\
\hline 8.23 & 3.03 & 9.91 & 5.18 & 9.69 & 10.20 & 9.73 & 12.01 & 8.80 & 6.62 & 8.74 & 12.78 \\
\hline 9.24 & 2.56 & 10.94 & 4.86 & 10.69 & 9.37 & 10.75 & 10.82 & 9.81 & 6.05 & 9.77 & 12.08 \\
\hline 10.26 & 2.25 & 11.95 & 4.29 & 11.73 & 8.67 & 12.78 & 10.22 & 10.82 & 5.69 & 10.78 & 11.35 \\
\hline 11.28 & 1.96 & 12.95 & 3.85 & 12.74 & 8.13 & 13.78 & 8.56 & 11.85 & 5.15 & 11.79 & 10.85 \\
\hline 12.27 & 1.89 & - & - & 13.77 & 7.81 & - & - & 12.86 & 4.91 & 12.81 & 10.46 \\
\hline \multicolumn{2}{|c|}{ SA15PA15 } & \multicolumn{2}{|c|}{ SC15PA15 } & \multicolumn{2}{|c|}{ SB15PA10 } & \multicolumn{2}{|c|}{ SB15PA20 } & \multicolumn{2}{|c|}{ SB15PB15 } & \multicolumn{2}{|c|}{ SB15PC15 } \\
\hline 0.00 & 61.29 & 0.00 & 66.04 & 0.00 & 59.00 & 0.00 & 58.07 & 0.00 & 68.49 & 0.00 & 65.02 \\
\hline 1.02 & 42.40 & 1.00 & 57.39 & 1.10 & 27.48 & 1.19 & 33.48 & 1.04 & 51.33 & 1.00 & 49.74 \\
\hline 2.38 & 30.29 & 2.44 & 30.67 & 2.44 & 31.26 & 2.44 & 31.98 & 2.42 & 32.29 & 2.42 & 33.70 \\
\hline 3.49 & 21.85 & 3.48 & 24.72 & 3.54 & 21.77 & 3.52 & 23.46 & 3.48 & 24.52 & 3.51 & 22.21 \\
\hline 4.56 & 14.59 & 4.55 & 21.30 & 4.56 & 17.08 & 4.58 & 16.44 & 4.56 & 19.84 & 4.59 & 14.79 \\
\hline 5.64 & 11.68 & 5.60 & 17.48 & 5.62 & 14.26 & 5.64 & 12.06 & 5.63 & 14.71 & 5.67 & 11.26 \\
\hline 6.70 & 9.87 & 6.64 & 14.79 & 6.65 & 12.70 & 6.70 & 9.50 & 6.69 & 11.40 & 6.71 & 9.06 \\
\hline 7.75 & 8.67 & 7.69 & 12.53 & 7.68 & 11.59 & 7.73 & 7.79 & 7.71 & 9.51 & 7.75 & 7.79 \\
\hline 8.76 & 7.85 & 8.73 & 10.65 & 8.71 & 10.62 & 8.77 & 6.52 & 8.74 & 8.15 & 8.79 & 6.72 \\
\hline 9.20 & 10.21 & 9.76 & 9.38 & 9.74 & 9.70 & 9.80 & 5.58 & 9.77 & 7.10 & 9.80 & 5.89 \\
\hline 10.82 & 6.45 & 10.79 & 8.04 & 10.74 & 9.07 & 10.82 & 4.91 & 10.81 & 6.29 & 10.83 & 5.27 \\
\hline 11.84 & 5.92 & 11.80 & 7.31 & 11.79 & 8.44 & 11.84 & 4.40 & 11.82 & 5.73 & 11.85 & 4.78 \\
\hline 12.84 & 5.52 & 12.82 & 6.47 & 12.79 & 7.92 & 12.85 & 4.07 & 12.84 & 5.21 & 12.88 & 4.55 \\
\hline 13.86 & 5.45 & - & - & 13.82 & 7.46 & 13.87 & 3.64 & 13.85 & 4.90 & 13.89 & 4.21 \\
\hline
\end{tabular}

$$
\begin{aligned}
& y=a x+(3-2 a) x^{2}+(a-2) x^{3} \quad 0<x<1, \\
& y=\frac{x}{b(x-1)^{2}+x} \quad x>1,
\end{aligned}
$$

where $x=\varepsilon_{\mathrm{c}} / \varepsilon_{\mathrm{cu}}, y=\sigma_{\mathrm{c}} / \sigma_{\mathrm{cu}}$, and $\sigma_{\mathrm{c}}$ and $\varepsilon_{\mathrm{c}}$ represent the axial stress and strain in which $\varepsilon_{\mathrm{cu}}$ and $\sigma_{\mathrm{cu}}$ are the axial strain and stress at peak point (transition point), as shown in Figure 10. The physical meaning of the parameter $a$, which controls the parabolic ascending portion of the stress-strain curve before the transition point reached, is the ratio of initial elastic modulus and tangential modulus at peak stress. From a regression analysis of the results in the current study and literature [7], the parameter $a$ is determined as the following:

$$
a=1.64+0.4772 \lambda_{\mathrm{sf}}-0.4917 \lambda_{\mathrm{pf}} .
$$

The $a$ value ranges from 1.5 to 3.0 . When the calculated value is less than 1.5 , it is set equal to 1.5 , and as the calculated value is larger than 3.0, it is equal to 3.0. The parameter $b$ that determines the slope of the descending branch is also related to the fiber reinforcing indexes. It enables to simulate the varying softening behaviors as the fiber parameter changes. The calculation of $b$ value is developed using Equation (9). It is noted that the effects of concrete strength are neglected during the evaluation of $a$ and $b$ values. The comparisons of parameters $a$ and $b$ between experimental and predicted results are shown in Figure 14, with reasonable agreements observed.

$$
b=1.185-0.501 \lambda_{\mathrm{sf}}-0.307 \lambda_{\mathrm{pf}}
$$

In addition, the $\varepsilon_{\mathrm{cu}}$ and $\sigma_{\mathrm{cu}}$ are also calculated as a function of fiber characteristic parameters from experimental results in the literature, as shown in Equation (10). The comparisons of peak stress and peak strain between experimental and predicted results are shown in Figure 15.

$$
\begin{aligned}
\sigma_{\mathrm{cu}} & =\sigma_{\mathrm{cu} 0}\left(1+0.179 \lambda_{\mathrm{sf}}+0.341 \lambda_{\mathrm{pf}}\right), \\
\varepsilon_{\mathrm{cu}} & =\varepsilon_{\mathrm{cu} 0}\left(1+0.55 \lambda_{\mathrm{sf}}+0.303 \lambda_{\mathrm{pf}}\right),
\end{aligned}
$$

where $\sigma_{\mathrm{cu} 0}$ and $\varepsilon_{\mathrm{cu} 0}$ represent the peak stress and peak strain for plain concrete. As a simplified format, the relationship between $\sigma_{\mathrm{cu} 0}$ and $\varepsilon_{\mathrm{cu} 0}$ is developed according to the literature [44] for convenient use, given as

$$
\varepsilon_{\mathrm{cu} 0}=263.3 \sqrt{\sigma_{\mathrm{cu} 0}} \cdot 10^{-6}
$$

5.2. Unloading Path. Considerable research results have shown that the unloading path from the envelope curve to the plastic strain point is nonlinear, which becomes significant when the unloading path intersects the strain axis. In addition, the shape of the unloading curve depends on the initial unloading point and ultimate unloading point $[24,26]$. In order to capture the aforementioned features in concrete cyclic response, many formulae have been developed [26-31, 43]. Among them, the power type of 

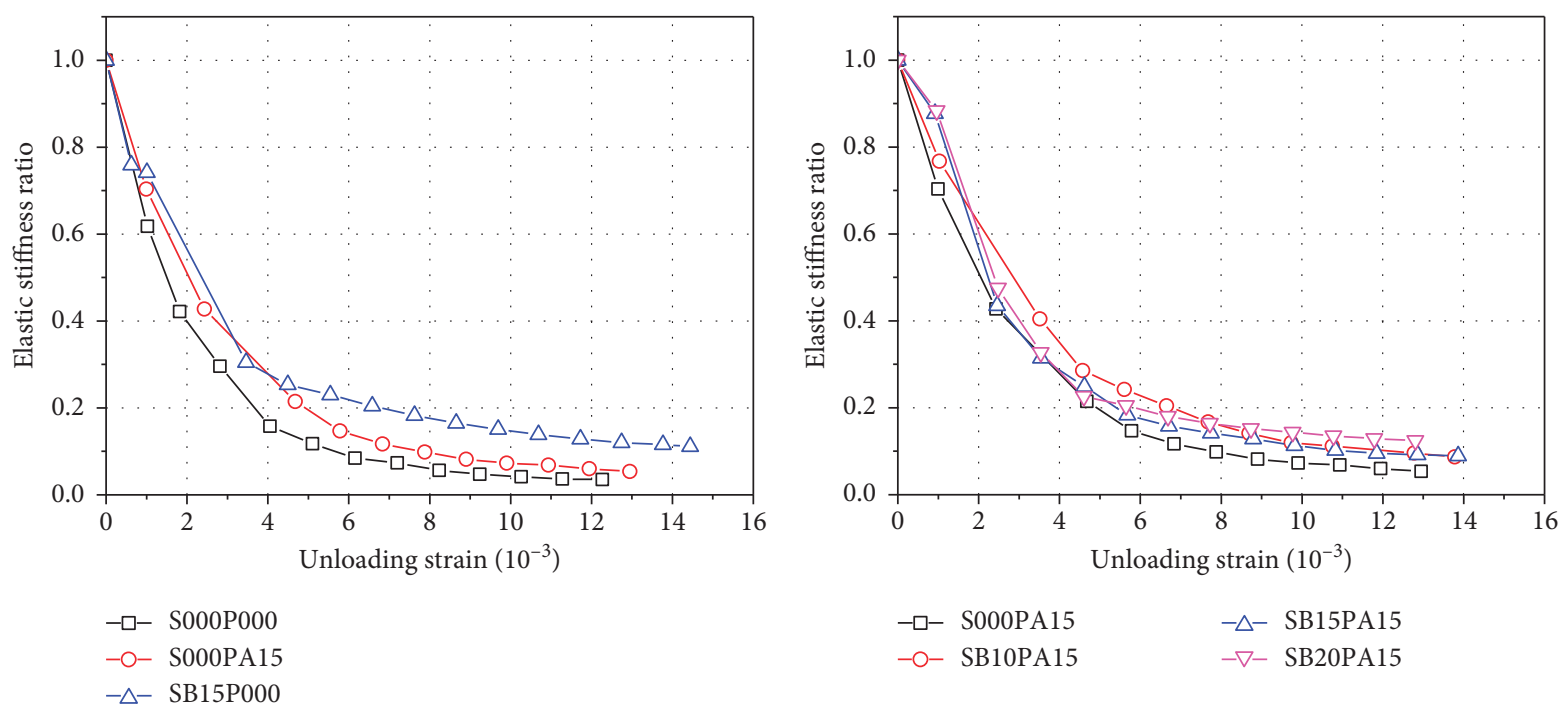

(a)

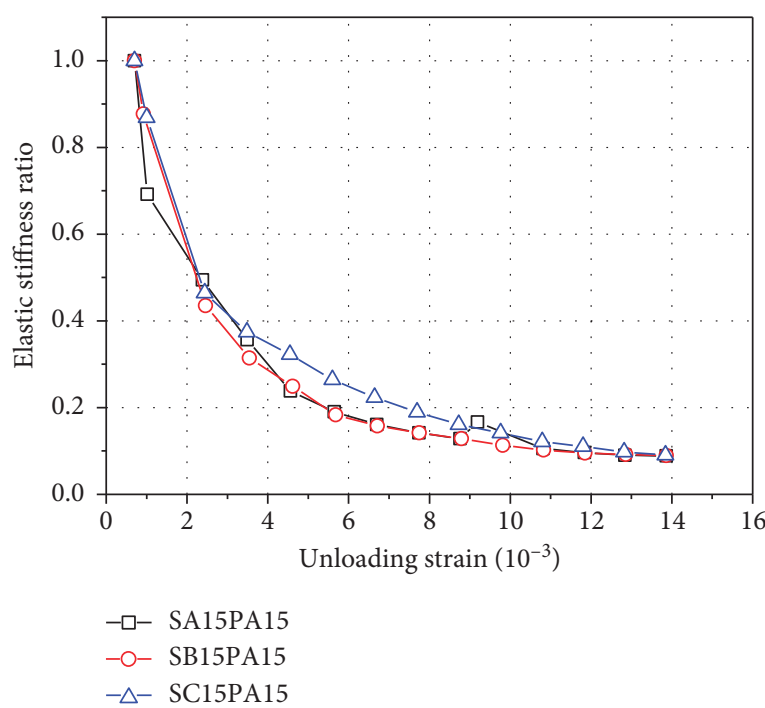

(b)

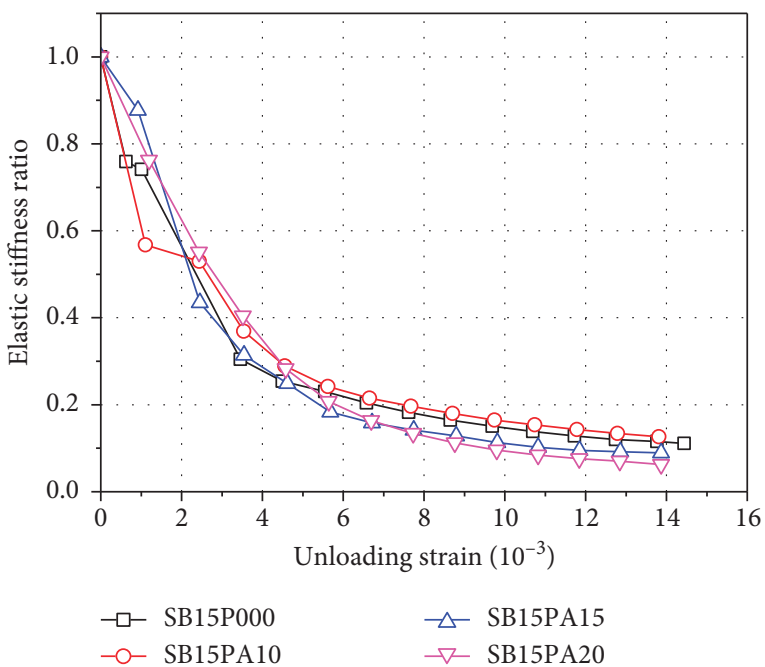

(c)

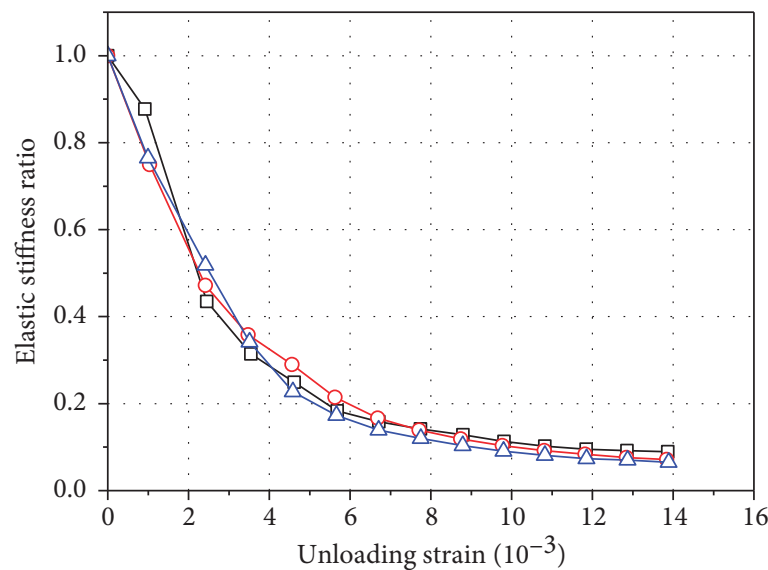

(d)

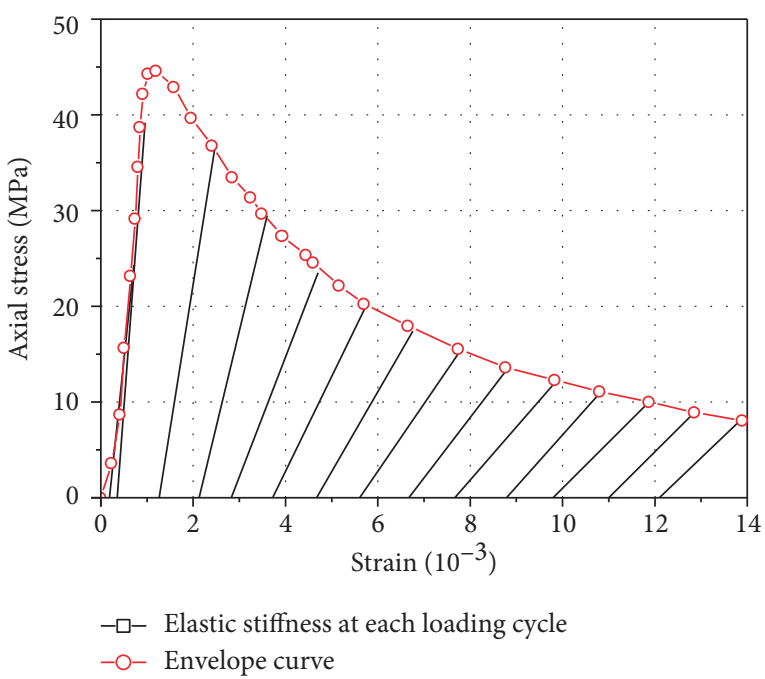

(e)

(f)

FIGURE 11: Relations between elastic stiffness degradation and envelope unloading strain. (a) Effect of fiber type; (b) effect of volume fraction of SF; (c) effect of aspect ratio of SF; (d) effect of volume fraction of PF; (e) effect of aspect ratio of PF; and (f) schematic diagram of typical elastic stiffness degradation process of BFRC. 


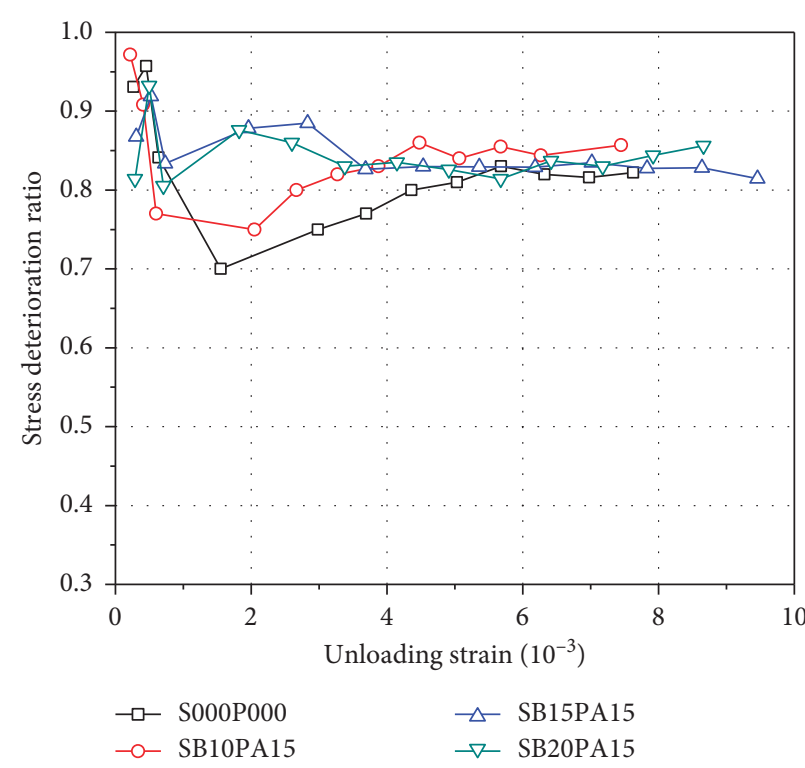

(a)

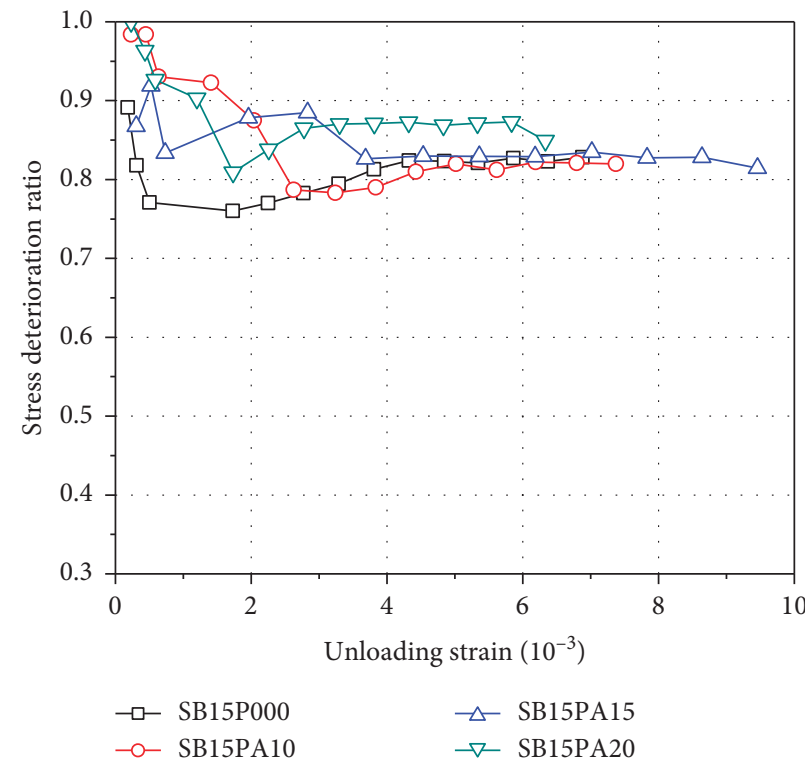

(c)

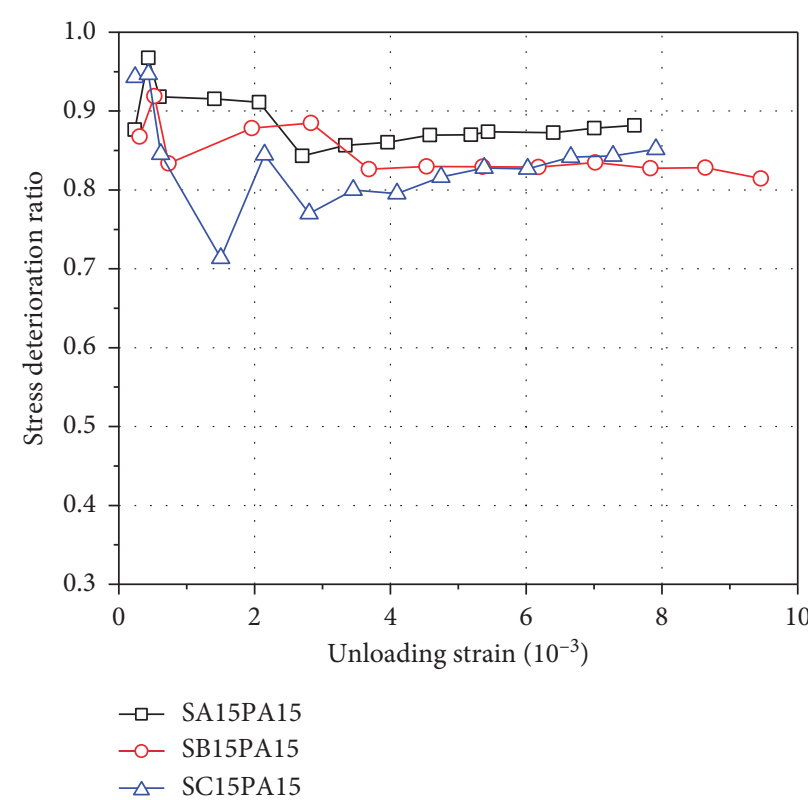

(b)

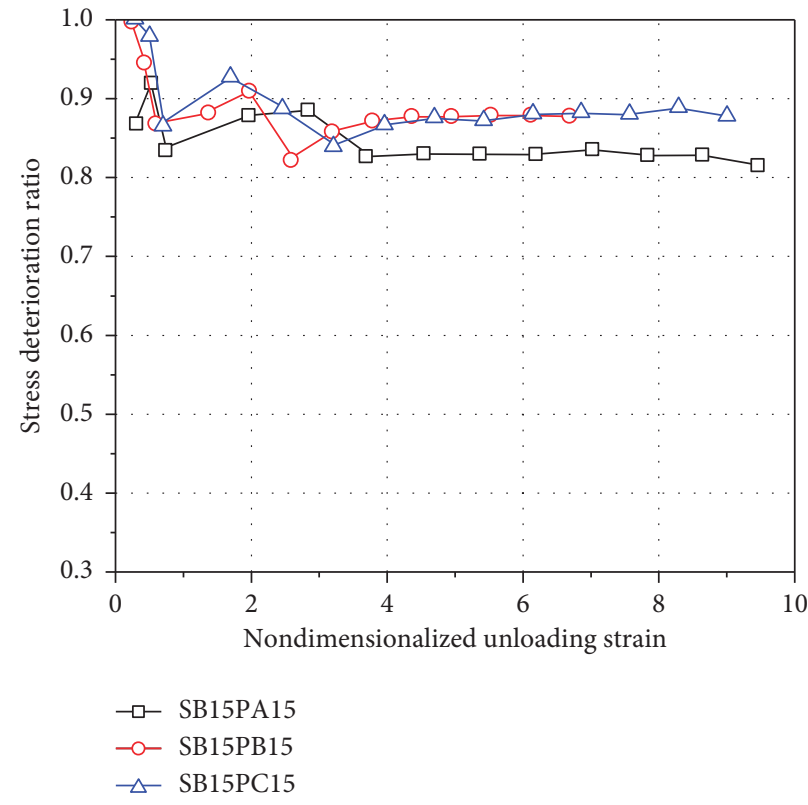

(d)

Figure 12: Relations between stress deterioration ratio and envelope unloading strain. (a) Effect of steel fiber volume fraction; (b) effect of steel fiber aspect ratio; (c) effect of polypropylene fiber volume fraction; and (d) effect of polypropylene fiber aspect ratio.

equation proposed by Bahn and Hsu [18] for modeling the behavior of unloading path can provide best estimation of the unloading curve. The equation reads as follows:

$$
\text { for linear unloading: } \frac{\sigma_{\mathrm{c}}}{\sigma_{\mathrm{unl}}}=\frac{\varepsilon_{\mathrm{c}}-\varepsilon_{\mathrm{pl}}}{\varepsilon_{\mathrm{unl}}-\varepsilon_{\mathrm{pl}}} \text {, }
$$

$$
\text { for nonlinear unloading: } \frac{\sigma_{\mathrm{c}}}{\sigma_{\mathrm{unl}}}=m\left(\frac{\varepsilon_{\mathrm{c}}-\varepsilon_{\mathrm{pl}}}{\varepsilon_{\mathrm{unl}}-\varepsilon_{\mathrm{pl}}}\right)^{n} \text {, }
$$

where $m$ and $n$ are the parameters of the unloading curve. $m$ is a coefficient of unloading curve which can be obtained by fitting the experimental results, with the value ranging between 0.95 and 1.0. In general, $m=1$ is assumed and adopted for the concrete material. The parameter $n$ controls the curvature of unloading path that relates to the envelope unloading strain closely [24-27]. By means of a regression analysis of the current test results, the formula is written as Equation (14), with the best fitting result shown in Figure 16.

$$
n=1+1.132\left(\frac{\varepsilon_{\mathrm{unl}}}{\varepsilon_{\mathrm{cu}}}\right)^{0.436}
$$




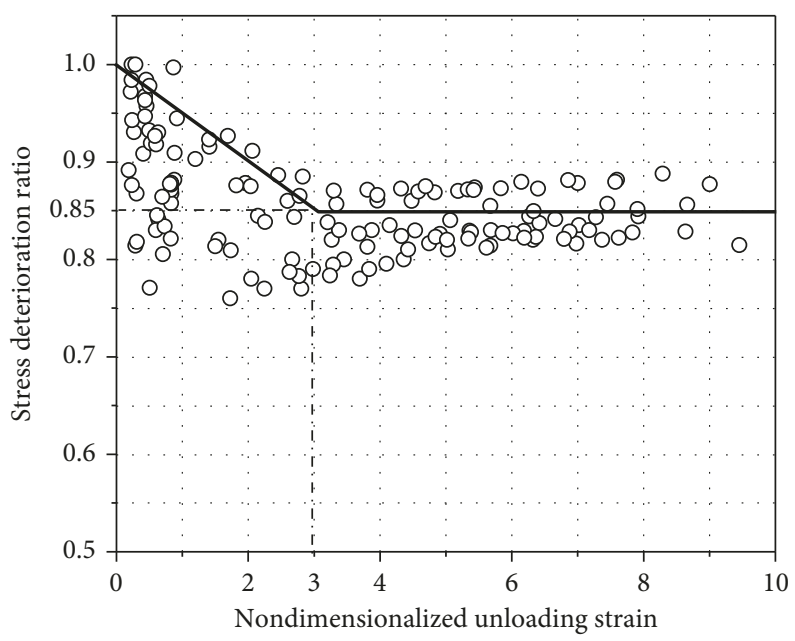

FIGURE 13: Relation between stress deterioration ratio and nondimensionalized unloading strain for BFRC.

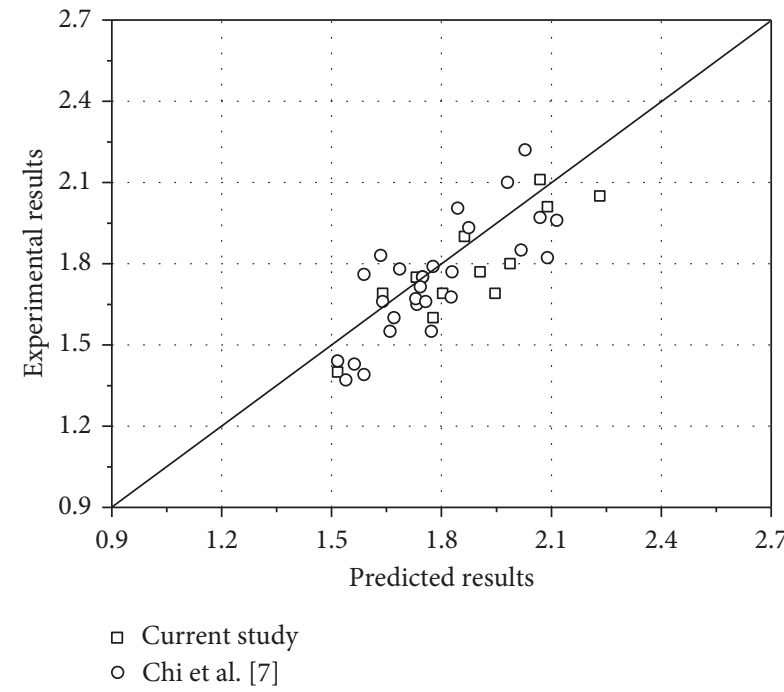

(a)

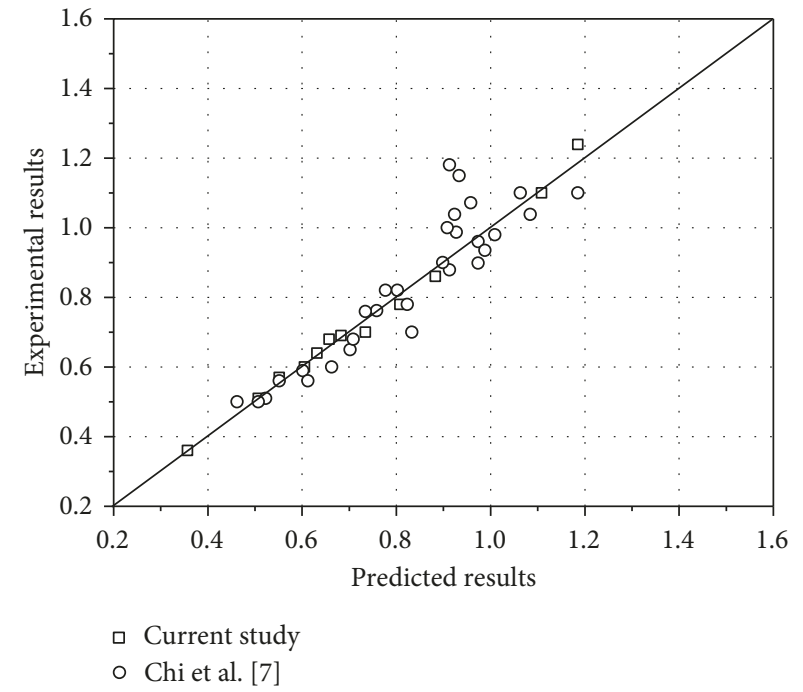

(b)

FIGURE 14: Comparisons of parameters between experimental and predicted results. (a) Parameter $a$; (b) parameter $b$.

5.3. Reloading Path. As aforementioned, the reloading path of a full cycle consists of a linear segment and a parabolic segment. At present, many equations have been proposed to simulate the reloading path, from linear function to nonlinear approximation. However, the predictions exhibit remarkable deviations in particular when the reloading path is approaching to the intersection point with the unloading curve. To tackle this problem, a sectional model $[26,43]$ is adopted and described by a broken line, as shown in Figure 10.

5.3.1. The First Linear Portion. The first linear portion of the reloading path is defined by the following equation:

$$
\sigma_{\mathrm{c}}=\frac{\sigma_{\mathrm{re}}}{\varepsilon_{\mathrm{unl}}-\varepsilon_{\mathrm{pl}}}\left(\varepsilon_{\mathrm{c}}-\varepsilon_{\mathrm{pl}}\right), \quad \varepsilon_{\mathrm{c}}<\varepsilon_{\mathrm{unl}},
$$

where $\sigma_{\text {re }}$ is the reloading transition point stress when the strain reaches the unloading strain $\varepsilon_{\text {unl }}$. According to Equation (5), $\sigma_{\text {re }}$ can be expressed as follows:

$$
\sigma_{\text {re }}=\varphi \sigma_{\text {unl }}
$$

5.3.2. The Second Linear Portion. The second linear portion of the reloading path is expressed by the following equation:

$$
\sigma_{\mathrm{c}}=\frac{\sigma_{\text {ret }}-\sigma_{\text {re }}}{\varepsilon_{\text {ret }}-\varepsilon_{\text {unl }}}\left(\varepsilon_{\mathrm{c}}-\varepsilon_{\text {unl }}\right)+\sigma_{\text {re }}, \quad \varepsilon_{\mathrm{c}}>\varepsilon_{\text {unl }},
$$

where the point $\left(\sigma_{\text {ret }}, \varepsilon_{\text {ret }}\right)$ is the intersection point of the reloading path and the envelope curve. The relationship between $\sigma_{\text {ret }}$ and $\varepsilon_{\text {ret }}$ can be determined by Equation (7). 


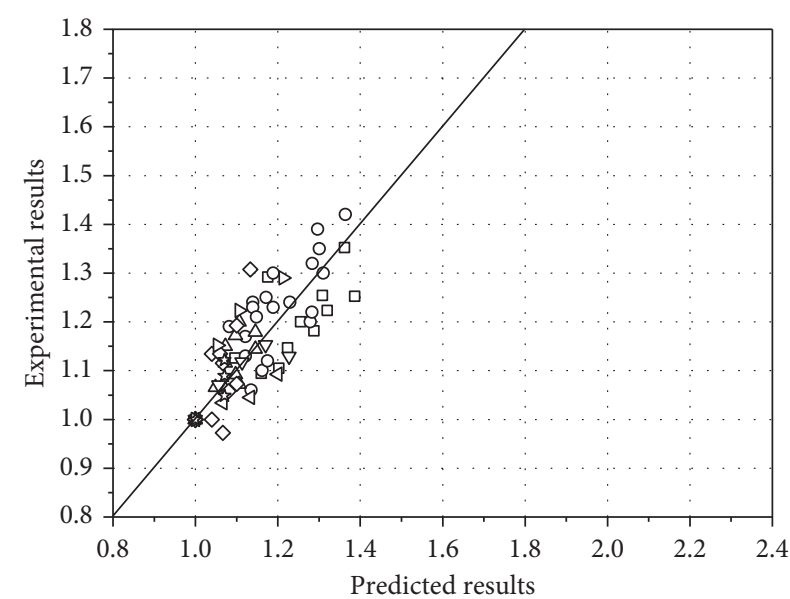
口 Current study
- Chi et al. [7]
$\diamond$ Ezeldin and Balaguru [45]
$\triangle$ Natajara et al. [2
$\nabla$ Song and Hwang [4]
$\triangleleft$ Wafa and Ashour [46]
$\triangleright$ Campione and Cucchiara [47]
\& Bencardino et al. [48]

(a)

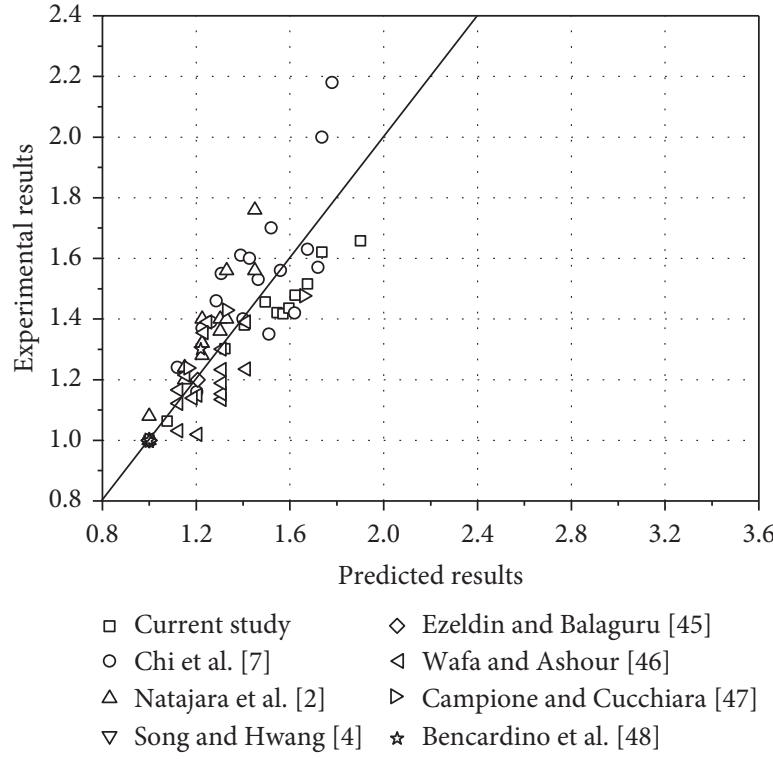

(b)

Figure 15: Comparisons of mechanical parameters between experimental [2, 4, 7, 45-48] and predicted results. (a) Peak stress; (b) peak strain.

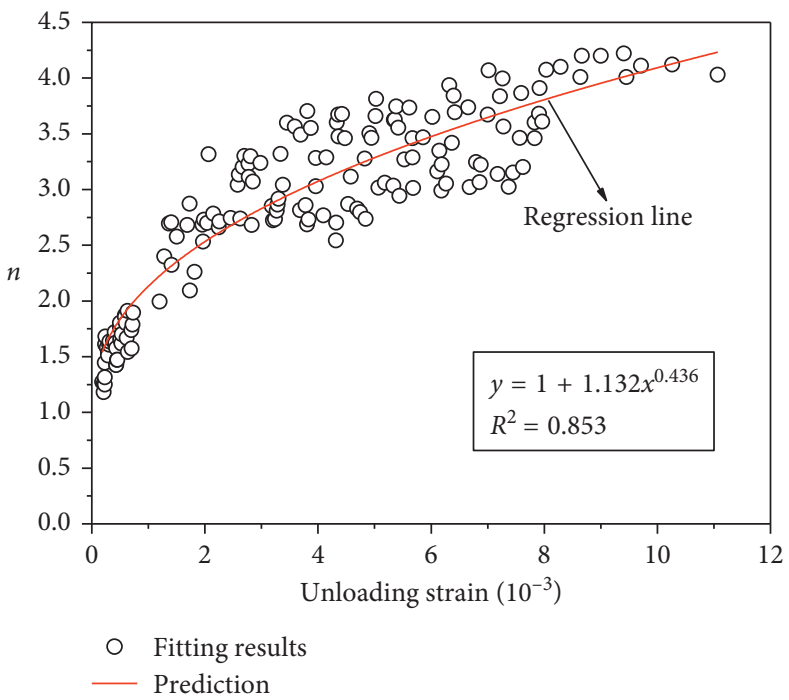

FIgURE 16: Variation of $n$ with $\varepsilon_{\text {unl }} / \varepsilon_{\mathrm{co}}$.

5.4. Partial Unloading and Reloading Path. For incomplete unloading, the unloading path of the stress-strain curve is interrupted at the point $\left(\varepsilon_{\text {rel }}, \sigma_{\text {rel }}\right)$ (Figure 10$)$. The partial unloading path followed by a reloading path can be assumed as a portion of the complete unloading curve. The model equation can be expressed as Equation (13). Assuming that no damage occurs during the unloading process [28-30], the reloading path can also use the broken line model as shown in Equations (15) and (17)

\section{Comparison of Experimental Tests and Proposed Models}

In order to facilitate better understanding and implementation, a step-by-step process for generating the stressstrain curves of BFRC under cyclic compression is summarized in Figure 17. For a given BFRC specimen, in addition to the concrete compressive strength $\left(\sigma_{\text {un }}\right)$ and fiber characteristic parameters of SF $\left(\lambda_{\mathrm{sf}}\right)$ and PF $\left(\lambda_{\mathrm{pf}}\right)$, only the experimental values of the unloading strain $\left(\varepsilon_{\text {unl }}\right)$ and the 


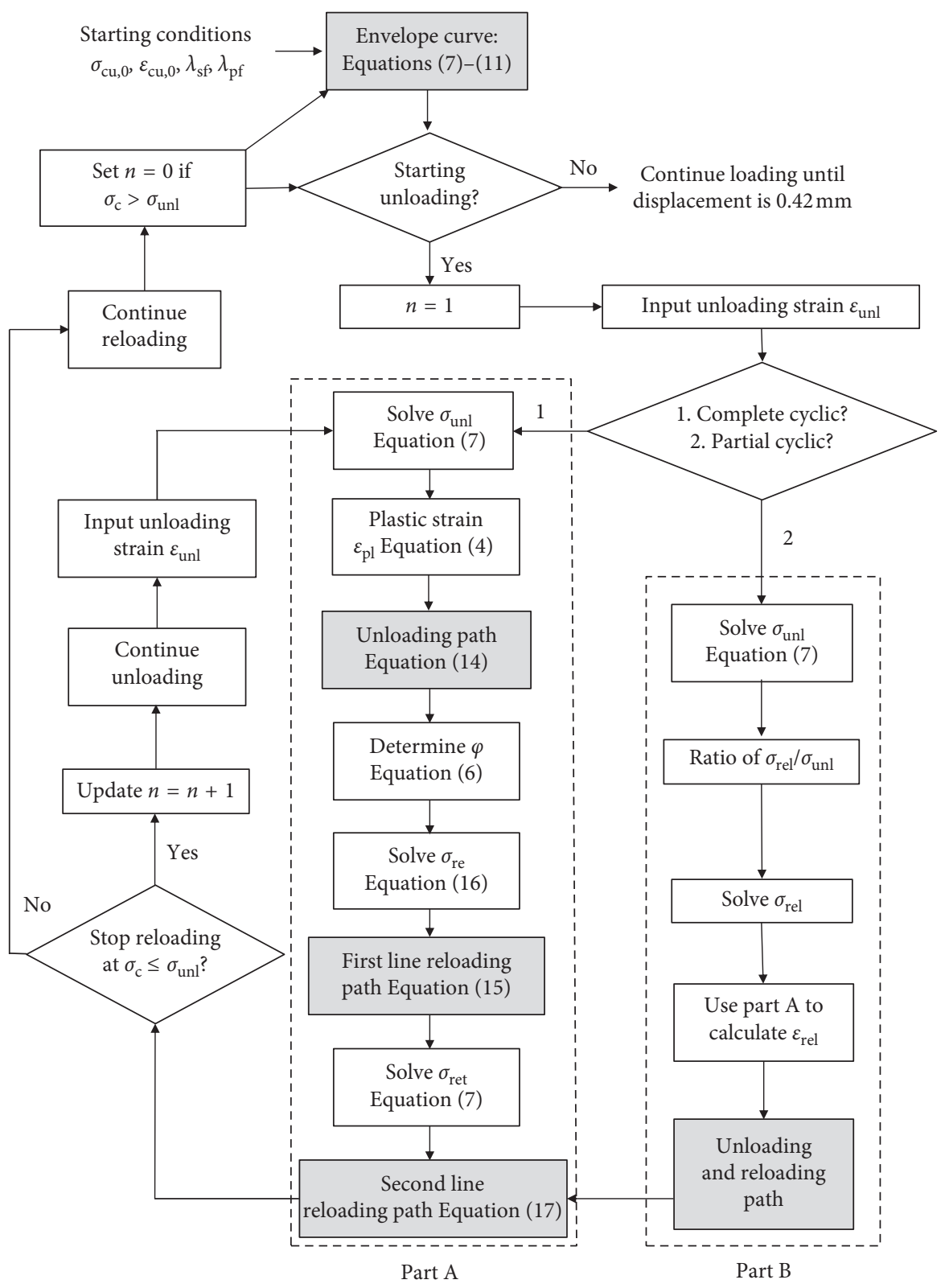

FIGURE 17: Flowchart describing the generation of stress-strain curves under cyclic compression.

partial unloading stress $\left(\sigma_{\text {rel }}\right)$ are used as the input parameters. The unloading stress $\left(\sigma_{\text {unl }}\right)$, the plastic strain $\left(\varepsilon_{\mathrm{pl}}\right)$, the stress and strain at the transition point $\left(\varepsilon_{\text {re }}, \sigma_{\text {re }}\right)$, and intersection point $\left(\varepsilon_{\text {ret }}, \sigma_{\text {ret }}\right)$ are all calculated from the above-proposed formulae.

Figure 18 shows the typical comparisons of the models' predictions with test results in this study and open literature for plain concrete, PFRC, SFRC, and BFRC, respectively. It is evident that despite slight discrepancies, the proposed models can provide fairly good estimation of cyclic stressstrain response of FRC.

However, it should be noted that the model for PFRC and BFRC is only validated based on the current test results due to the lack of test data in the literature.

\section{Conclusions}

(i) The introduction of blended fibers into concrete matrix has positive influences on improving the mechanical behavior of concrete under cyclic loading, reflected in that an improvement on peak strength and postpeak ductility can be observed, notwithstanding that PF has an insignificant effect for ductility. The failure pattern of BFRC is ductile, while that of plain concrete is brittle.

(ii) Obvious degradation on elastic stiffness and strength with increasing loading cycles is observed, especially on the postpeak region. The capacity of FRC in hysteretic energy dissipation is stronger than 


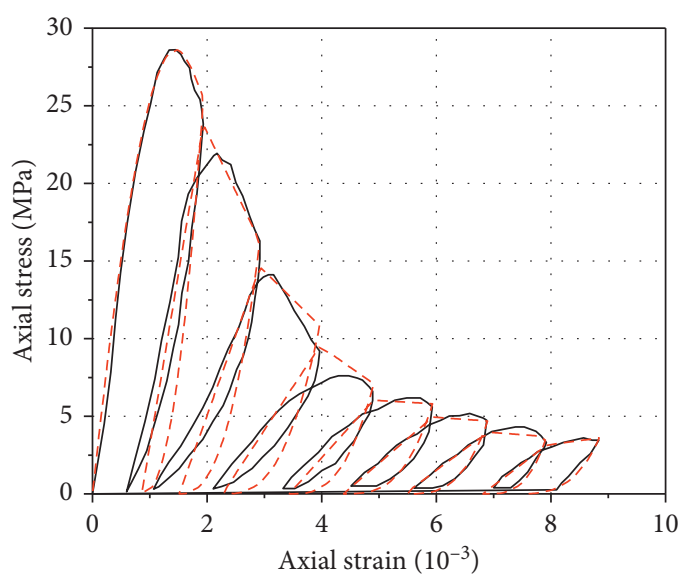

S000P000

— Karsan and Jirsa [14]

- - - Proposed model

(a)

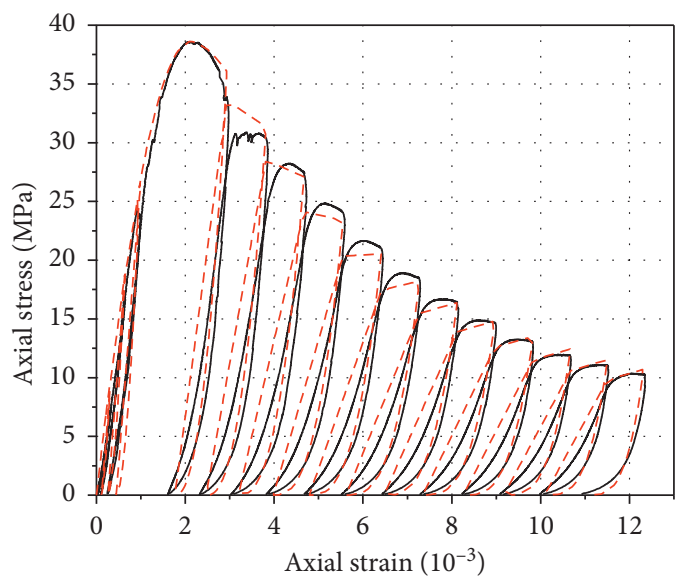

SB10P000

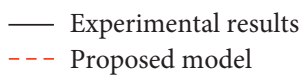

(c)

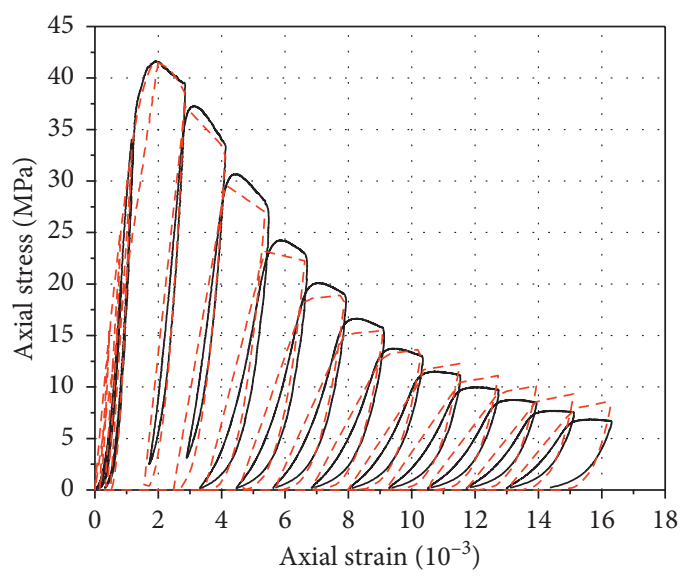

SB10PA10

- Experimental results

- - - Proposed model

(e)

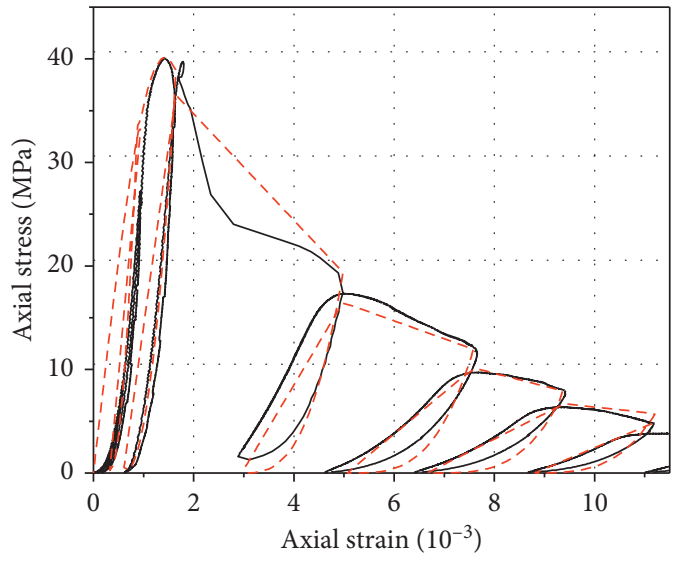

S000PC15

- Experimental result

- - - Proposed model

(b)

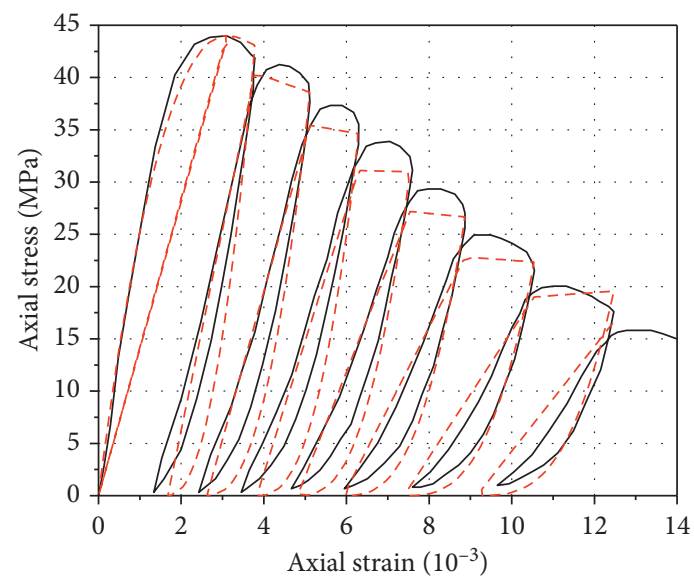

SB20P000

- Otter and Naaman [34]

- - - Proposed model

(d)

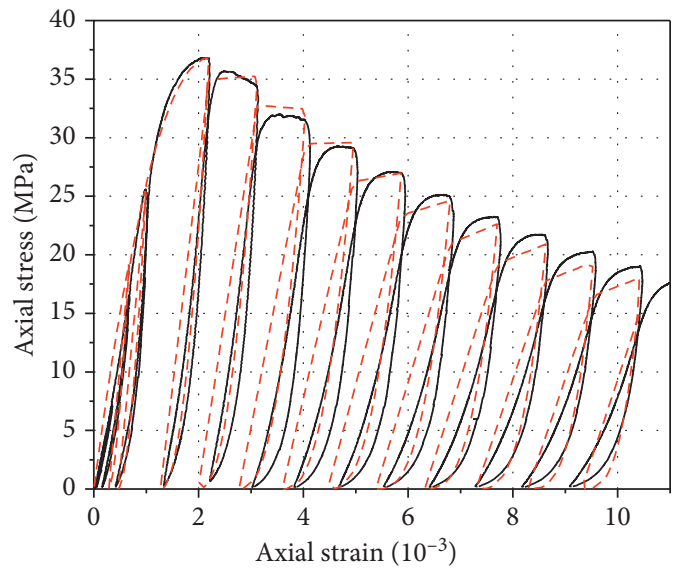

SB20PA20

- Experimental results

- - - Proposed model

(f)

Figure 18: Typical comparisons of experimental results and proposed models for concrete. 
that of plain concrete. With respect to SFRC and BFRC, the energy dissipation remains active owing to the steel fiber sliding and pull-out mechanisms.

(iii) In comparison with plain concrete, the increase in volume fractions of both fibers can lead to a remarkable decrease in plastic strain accumulation. The stiffness degradation ratio as well as the stress deterioration ratio of BFRC is significantly alleviated in comparison with those of plain concrete, despite the degradation degrees being insensitive to the variations of fiber parameters.

(iv) A semiempirical constitutive model for BFRC under uniaxial cyclic compression is developed to generalize the cyclic stress-strain response, with the contributions of blended fiber taken into consideration. The predictions are found in satisfactory agreement with the results in this study and other literature.

\section{Data Availability}

All the data underlying the findings of the study can be found in the tables in the article.

\section{Conflicts of Interest}

The authors declare that they have no conflicts of interest.

\section{Acknowledgments}

The present work was supported by the Chinese National Natural Science Foundation (Grant nos. 51608397 and 51478367). The financial support is gratefully acknowledged.

\section{References}

[1] T. H. Wee, M. S. Chin, and M. A. Mansur, "Stress-strain relationship of high-strength concrete in compression," Journal of Materials in Civil Engineering, vol. 8, no. 2, pp. 70-76, 1996.

[2] M. C. Nataraja, N. Dhang, and A. P. Gupta, "Stress-strain curves for steel-fiber reinforced concrete under compression," Cement \& Concrete Composites, vol. 21, no. 5-6, pp. 383-390, 1999.

[3] M. H. Zhang, L. Li, and P Paramasivam, "Flexural toughness and impact resistance of steel-fibre-reinforced lightweight concrete," Magazine of Concrete Research, vol. 56, no. 5, pp. 251-262, 2004.

[4] P. S. Song and S. Hwang, "Mechanical properties of highstrength steel fiber-reinforced concrete," Construction and Building Materials, vol. 18, no. 9, pp. 669-673, 2004.

[5] A. M. Brandt, "Fibre reinforced cement-based (FRC) composites after over 40 years of development in building and civil engineering," Composite Structures, vol. 86, no. 1-3, pp. 3-9, 2008.

[6] H. D. Yun, F. Fukuyama, E. Jeon, I. S. Yang, and C. S. Choi, "Mechanical properties of high-performance hybrid-fibrereinforced cementitious composites (HPHFRCCs)," Magazine of Concrete Research, vol. 59, no. 4, pp. 257-271, 2007.

[7] Y. Chi, L. H. Xu, and Y. Zhang, "Experimental study on hybrid fiber-reinforced concrete subject to uniaxial compression," Journal of Materials in Civil Engineering, vol. 26, no. 2, pp. 211-218, 2014.
[8] Y. Chi, L. H. Xu, and H. S. Yu, "Constitutive modeling of steelpolypropylene hybrid fiber reinforced concrete using a nonassociated plasticity and its numerical implementation," Composite Structures, vol. 111, no. 1, pp. 497-509, 2014.

[9] S. B. Daneti and T. H. Wee, "Behaviour of hybrid fibre reinforced high-strength lightweight aggregate concrete," Magazine of Concrete Research, vol. 63, no. 11, pp. 785-796, 2011.

[10] L. H. Xu, L. Huang, Y. Chi, and G. D. Mei, "Tensile behavior of steel-polypropylene hybrid fiber-reinforced concrete," $A C I$ Materials Journal, vol. 2, no. 113, pp. 219-229, 2016.

[11] H. Fathi and H. Dabbagh, "Damage mechanism of SCC under cyclic loading with different speed," Construction and Building Materials, vol. 101, no. 1, pp. 252-259, 2015.

[12] M. Nehdi, A. Said, and M. Elmorsi, "Non-linear model for reinforced concrete under cyclic loading," Magazine of Concrete Research, vol. 57, no. 4, pp. 211-224, 2005.

[13] B. P. Sinha, K. H. Gerstle, and L. G. Tulin, "Stress-strain relations for concrete under cyclic loading," ACI Structural Journal, vol. 61, no. 2, pp. 195-211, 1964.

[14] L. D. Karsan and J. O. Jirsa, "Behavior of concrete under compression loadings," Journal of Structural Division, vol. 95, no. 12, pp. 2543-2563, 1969.

[15] D. Z. Yankelevsky and H. W. Rainhardt, "Uniaxial behavior of concrete under cyclic loading," Journal of Structural Engineering, vol. 115, no. 1, pp. 166-182, 1989.

[16] Y. H. Lee and K. J. Willan, "Mechanical properties of concrete under cyclic compression," ACI Materials Journal, vol. 94, pp. 457-467, 1997.

[17] K. Maekawa and K. F. EI-Kashif, "Cyclic cumulative damaging of reinforced concrete in post-peak regions," Journal of Advanced Concrete Technology, vol. 2, no. 2, pp. 257-271, 2004.

[18] B. Y. Bahn and C. T. T. Hsu, "Stress-strain behavior of concrete under cyclic loading," ACI Materials Journal, vol. 95, no. 2, pp. 178-193, 1988.

[19] E. Osorio, J. M. Bairan, and A. R. Mari, "Lateral behavior of concrete under uniaxial compressive cyclic loading," Materials and Structures, vol. 46, no. 5, pp. 709-724, 2013.

[20] S. Sinaie, A. Heidarpour, X. L. Zhao, and J. G. Sanjayan, "Effect of size on the response of cylindrical concrete samples under cyclic loading," Construction and Building Materials, vol. 84, no. 1, pp. 399-408, 2015.

[21] H. P. Lee, A. Z. Awang, and W. Omar, "Steel strap confined high strength concrete under uniaxial cyclic compression," Construction and Building Materials, vol. 72, no. 1, pp. 48-55, 2014.

[22] H. K. Cheong and S. H. Perry, "Cyclic loading of laterally confined concrete columns," Materials and Structures, vol. 26, no. 9, pp. 557-562, 1993.

[23] R. Abbasnia and H. Ziaadiny, "Behavior of concrete prisms confined with FRP composites under axial cyclic compression," Engineering Structures, vol. 32, no. 3, pp. 648-655, 2010.

[24] Z. Y. Wang, D. Y. Wang, S. T. Smith, and D. G. Lu, "CFRPconfined square RC columns. I: experimental investigation," Journal of Composites for Construction, vol. 16, no. 2, pp. 150-160, 2012.

[25] L. Lam, J. G. Teng, C. H. Cheung, and Y. Xiao, "FRP-confined concrete under axial cyclic compression," Cement \& Concrete Composites, vol. 28, no. 10, pp. 949-958, 2006.

[26] L. Lam and J. G. Teng, "Stress-strain model for FRP-confined concrete under cyclic axial compression," Engineering Structures, vol. 31, no. 2, pp. 308-321, 2009. 
[27] N. F. Hany, E. G. Hantouche, and M. H. Harajli, “Axial stressstrain model of CFRP-confined concrete under monotonic and cyclic loading," Journal of Composites for Construction, vol. 19, no. 6, pp. 1-16, 2015.

[28] Z. Y. Wang, D. Y. Wang, S. T. Smith, and D. G. Lu, "CFRPconfined square RC columns. II: cyclic axial compression stress-strain model," Journal of Composites for Construction, vol. 16, no. 2, pp. 161-170, 2012.

[29] J. F. Sima, P. Roca, and C. Molins, "Cyclic constitutive model for concrete," Engineering Structures, vol. 30, no. 3, pp. 695-706, 2008.

[30] M. Breccolotti, M. F. Bonfigli, A. D'Alessandro, and A. L. Materazzi, "Constitutive modeling of plain concrete subjected to cyclic uniaxial compressive loading," Construction and Building Materials, vol. 94, pp. 172-180, 2015.

[31] W. He, Y. F. Wu, and K. M. Liew, "A fracture energy based constitutive model for the analysis of reinforced concrete structures under cyclic loading," Computer Methods in Applied Mechanics \& Engineering, vol. 197, no. 51-52, pp. 4745-4762, 2008.

[32] M. Neuenschwander, M. Knobloch, and M. Fontana, "Suitability of the damage-plasticity modeling concept for concrete at elevated temperatures: experimental validation with uniaxial cyclic compression tests," Cement and Concrete Research, vol. 79, no. 2, pp. 57-75, 2016.

[33] D. E. Otter and A. E. Naaman, "Model for response of concrete to random compressive loads," Journal of Structural Engineering, vol. 115, no. 11, pp. 2794-2809, 1989.

[34] D. E. Otter and A. E. Naaman, "Properties of steel fiber reinforced concrete under cyclic load," ACI Materials Journal, vol. 85, no. 4, pp. 254-261, 1988.

[35] K. Komlos and B. Babal, "Hybrid fibre-reinforced concrete under repeated loading," Nuclear Engineering Design, vol. 156, no. 1, pp. 195-200, 1995.

[36] G. Campione and L. L. Mendola, "Stress-strain behavior in compression of lightweight fiber reinforced concrete under monotonic and cyclic loads," Earthquake Resitant Engineering Structures III, vol. 57, no. 9, pp. 387-396, 2001.

[37] B. Li, L. Xu, Y. Chi, B. Huang, and C. Li, "Experimental investigation on the stress-strain behavior of steel fiber reinforced concrete subjected to uniaxial cyclic compression," Construction and Building Materials, vol. 140, no. 1, pp. 109-118, 2017.

[38] Y. Tangawa and S. Hatanaka, "Stress-strain relations of steel fiber reinforced concrete under repeated compressive load," Cement and Concrete Research, vol. 13, no. 6, pp. 801-808, 1983.

[39] L. Huang, L. H. Xu, Y. Chi, and H. R. Xu, "Experimental investigation on the seismic performance of steelpolypropylene hybrid fiber reinforced concrete columns," Construction and Building Materials, vol. 87, no. 1-2, pp. 16-27, 2015.

[40] N. Ganesan, P. V. Indira, and M. V. Sabeena, "Behavior of hybrid fibre reinforced concrete beam-column joints under reverse cyclic loads," Materials \& Design, vol. 54, no. 2, pp. 686-693, 2014.

[41] JGJ 55-2011, Specification for Mix Proportion Design of Ordinary Concrete, Ministry of House and Urban-Rural Development of People's Republic of China, Beijing, China, 2011.

[42] CSCE 38, Technical Specification for Fiber Reinforced Concrete Structures, China Association for Engineering Construction Standardization, China, Beijing, China, 2004.
[43] J. Sakai and K. Kawashima, "Unloading and reloading stressstrain model for confined concrete," Journal of Structural Engineering, vol. 132, no. 1, pp. 112-22, 2006.

[44] Z. H. Guo and X. Q. Zhang, "Experimental investigation of the complete stress-strain curve of concrete," Journal of Building Structures, vol. 3, no. 1, pp. 1-12, 1982, in Chinese.

[45] A. S. Ezeldin and P. N. Balaguru, "Normal- and high-strength fiber reinforced concrete under compression," Journal of Materials in Civil Engineering, vol. 4, no. 4, pp. 415-429, 1992.

[46] F. F. Wafa and S. A. Ashour, "Mechanical properties of highstrength fiber reinforced concrete," ACI Materials Journal, vol. 88, no. 6, pp. 449-455, 1992.

[47] G. Campione and C. Cucchiara, "Steel-concrete bond in lightweight fiber reinforced concrete under monotonic and cyclic actions," Engineering Structures, vol. 27, no. 6, pp. 881-890, 2005.

[48] F. Bencardino, L. Rizzuti, and G. Spadea, "Experimental tests v/s theoretical modeling for FRC in compression," in Proceedings of 6th International Conference on Fracture Mechanics of Concrete and Concrete Structures-FraMCoS-6, vol. 3, pp. 1473-1480, Catania, Italty, June 2007. 


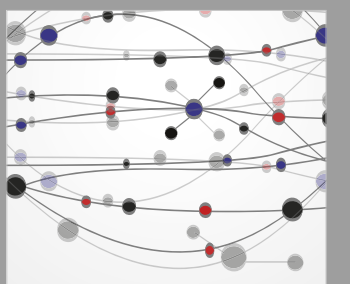

The Scientific World Journal
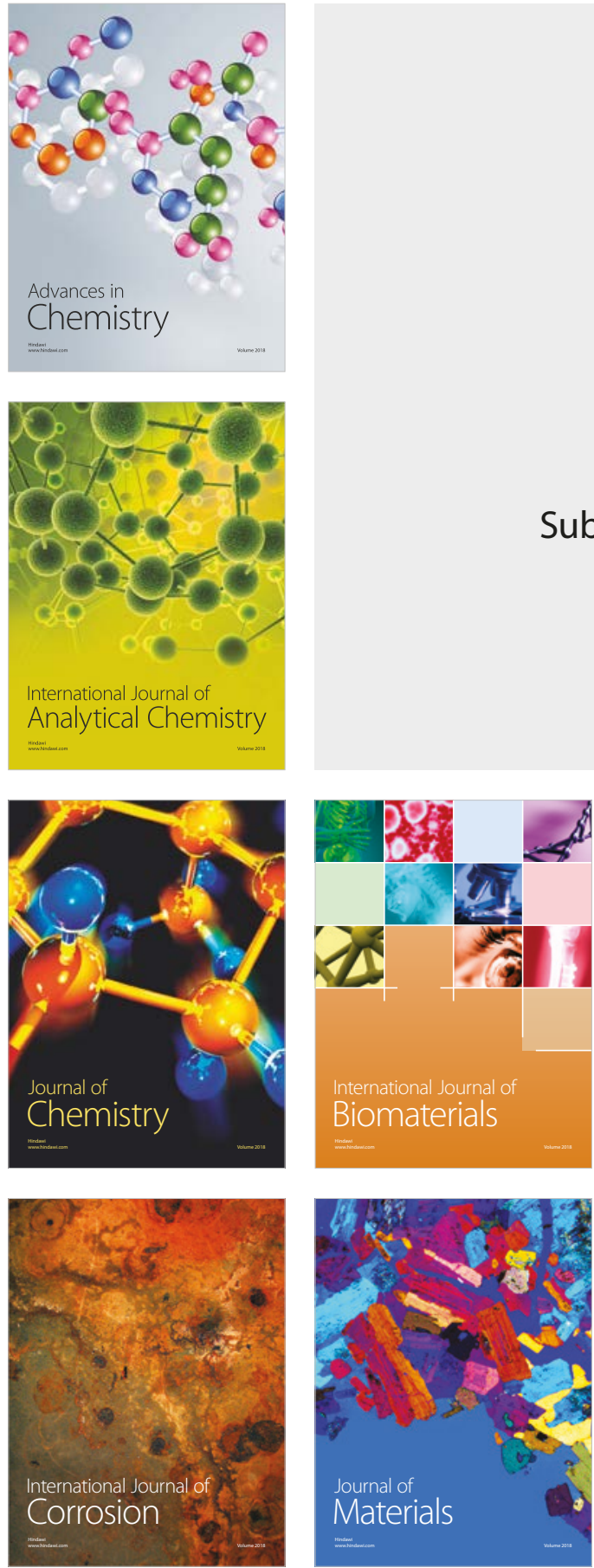

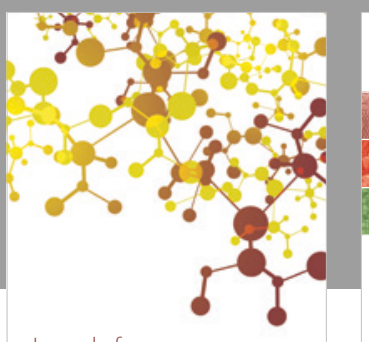

Journal of

Applied Chemistry
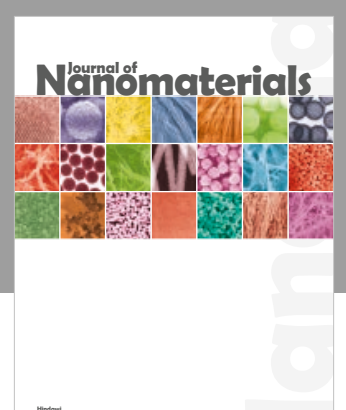

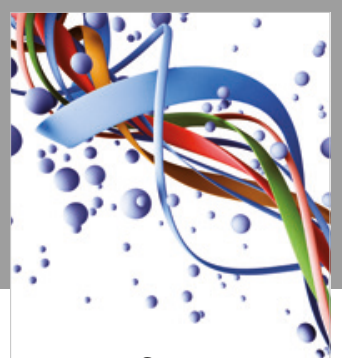

Scientifica

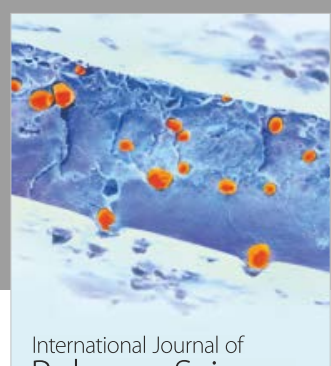

Polymer Science

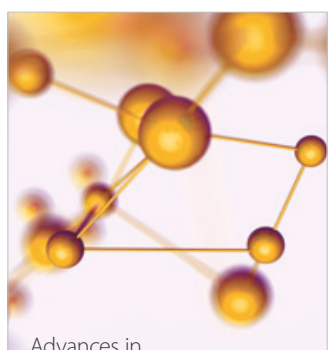

Physical Chemistry
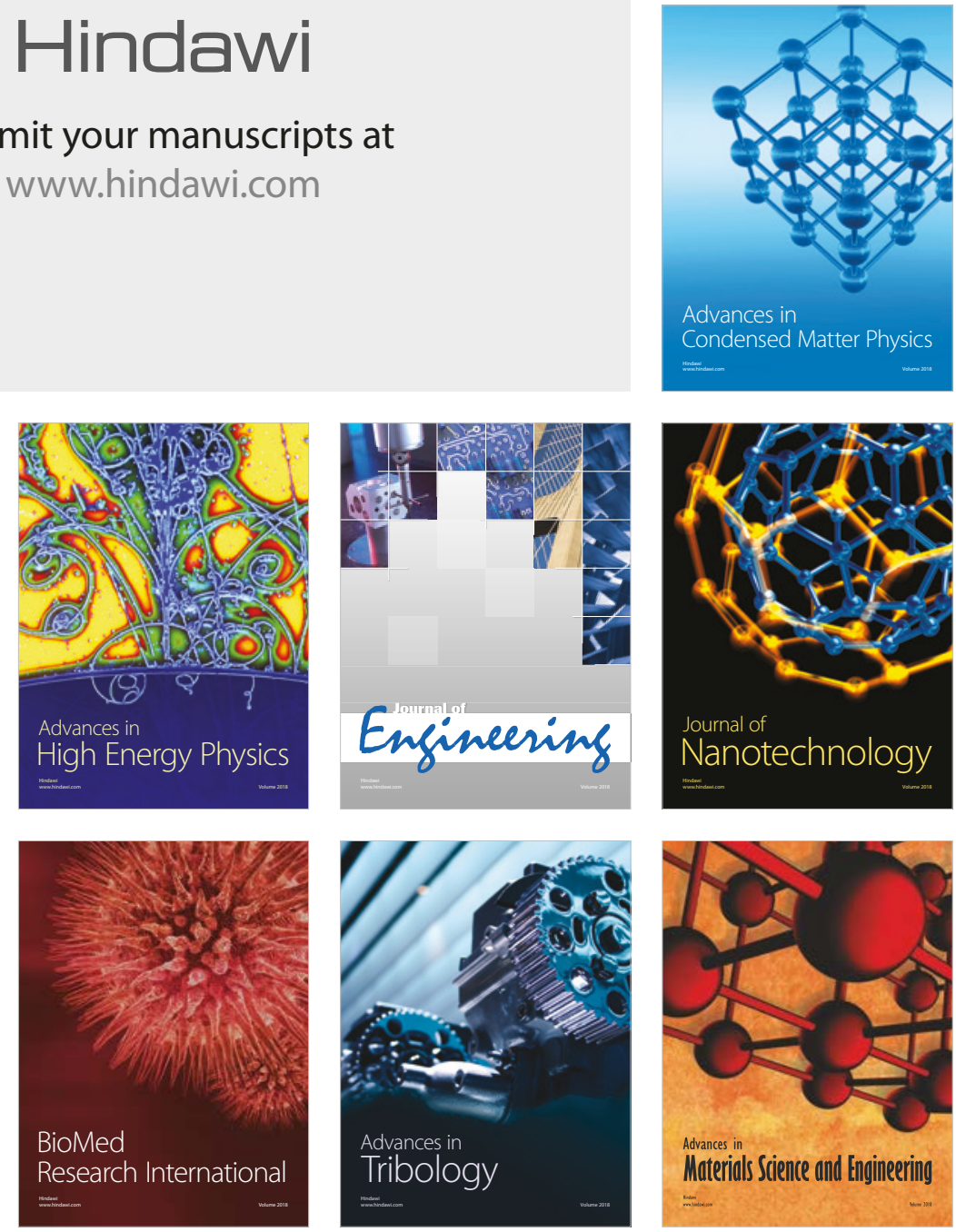